\title{
Synaptic remodeling generates synchronous oscillations in the degenerated outer mouse retina
}

\author{
Wadood Haq ${ }^{1,2,3}$, Blanca Arango-Gonzalez ${ }^{1}$, Eberhart Zrenner ${ }^{1,2,3}$, Thomas Euler ${ }^{1,2,3 *}$ and \\ Timm Schubert ${ }^{1,2 *}$
}

' Centre for Ophthalmology, Institute for Ophthalmic Research, University of Tübingen, Tübingen, Germany

${ }^{2}$ Werner Reichardt Centre for Integrative Neuroscience (CIN), University of Tübingen, Tübingen, Germany

${ }^{3}$ Bernstein Center for Computational Neuroscience Tübingen, University of Tübingen, Tübingen, Germany

Edited by:

Rachel O. Wong, University of

Washington, USA

Reviewed by:

David J. Margolis, Rutgers

University, USA

Daniel Kerschensteiner, Washington

University in St. Louis, USA

\section{${ }^{*}$ Correspondence:}

Thomas Euler and Timm Schubert,

Werner Reichardt Centre for

Integrative Neuroscience (CIN),

Institute for Ophthalmic Research,

University of Tübingen,

Otfried-Müller-Str. 25, 72076

Tübingen, Germany

e-mail: timm.schubert@

cin.uni-tuebingen.de; thomas.euler@

cin.uni-tuebingen.de
During neuronal degenerative diseases, neuronal microcircuits undergo severe structural alterations, leading to remodeling of synaptic connectivity. The functional consequences of such remodeling are mostly unknown. For instance, in mutant $r d 1$ mouse retina, a common model for Retinitis Pigmentosa, rod bipolar cells (RBCs) establish contacts with remnant cone photoreceptors (cones) as a consequence of rod photoreceptor cell death and the resulting lack of presynaptic input. To assess the functional connectivity in the remodeled, light-insensitive outer $r d 1$ retina, we recorded spontaneous population activity in retinal wholemounts using $\mathrm{Ca}^{2+}$ imaging and identified the participating cell types. Focusing on cones, RBCs and horizontal cells (HCs), we found that these cell types display spontaneous oscillatory activity and form synchronously active clusters. Overall activity was modulated by GABAergic inhibition from interneurons such as HCs and/or possibly interplexiform cells. Many of the activity clusters comprised both cones and RBCs. Opposite to what is expected from the intact (wild-type) cone-ON bipolar cell pathway, cone and RBC activity was positively correlated and, at least partially, mediated by glutamate transporters expressed on RBCs. Deletion of gap junctional coupling between cones reduced the number of clusters, indicating that electrical cone coupling plays a crucial role for generating the observed synchronized oscillations. In conclusion, degeneration-induced synaptic remodeling of the $r d 1$ retina results in a complex self-sustained outer retinal oscillatory network, that complements (and potentially modulates) the recently described inner retinal oscillatory network consisting of amacrine, bipolar and ganglion cells.

Keywords: degeneration, synapse remodeling, photopsia, retina, glutamate transporter

\section{INTRODUCTION}

The mutant $r d 1$ mouse (Bowes et al., 1990) is an intensively studied animal model for human Retinitis Pigmentosa-related retinal degeneration. In the $r d 1$ retina, rod photoreceptors (rods) start degenerating around postnatal day $10(\mathrm{P} 10)$ and are virtually absent by P21 (Carter-Dawson et al., 1978; Jimenez et al., 1996). During this progressive rod degeneration, cones, although not directly affected by the $r d 1$ mutation, undergo secondary degeneration. Some atrophied cones remain in the outer retina for over 1 year (Garcia-Fernandez et al., 1995). However, with the loss of cone outer segments after P24 (Lin et al., 2009), light-evoked retinal activity is absent in the $r d 1$ retina (Stasheff, 2008), thus, the disease leads to complete blindness within the first postnatal month.

Loss of light-driven activity is accompanied by a dramatic increase in spontaneous activity of the inner retina: such activity has been described in bipolar cells (Borowska et al., 2011) and ganglion cells (Margolis et al., 2008). It was suggested that AII amacrine cells and ON-cone bipolar cells form an intrinsic oscillator that serves as a potential source of this spontaneous activity (Borowska et al., 2011; Menzler and Zeck, 2011; Trenholm et al., 2012). In the healthy retina, AIIs receive glutamatergic input exclusively from rod bipolar cells (RBCs) (for review, see Bloomfield and Dacheux, 2001). However, if spontaneous activity in the AII/ON-cone bipolar cell network of $r d 1$ retina is intrinsic or modulated by RBCs has remained unclear.

In the outer $r d 1$ retina, cones and RBCs undergo structural synaptic remodeling: cones establish ectopic synapses with RBC somata (Peng et al., 2000). Rod bipolar cells lose their dendrites and down-regulate expression of metabotropic glutamate receptor 6 (mGluR6) (Strettoi and Pignatelli, 2000) as well as the respective effector cation channel TRPM1 (Krizaj et al., 2010) but remain active (Borowska et al., 2011). It is conceivable that the substantial remodeling of the $r d 1$ retina following photoreceptor loss leads to generation of spontaneous activity in the outer retina, which may contribute to or modulate the oscillatory activity observed in the inner retina. Investigating activity in the remodeled outer $r d 1$ retina is important as it improves our understanding of the general synaptic mechanisms underlying spontaneous activity in degenerated nervous tissue. Moreover, it is crucial to identify potential means for spontaneous activity 
suppression (Toychiev et al., 2013), which may greatly improve e.g., the responsiveness of the degenerated retina to optogenetic approaches (Lagali et al., 2008; Busskamp et al., 2010) and electronic implants (Zrenner et al., 2011; Zrenner, 2013) as treatments for vision loss.

Here, we studied neuronal activity in the outer retina of adult $r d 1$ mice using $\mathrm{Ca}^{2+}$ imaging and consecutive immunohistochemistry. We investigated how synaptic remodeling alters network function and found spontaneous, synchronized $\mathrm{Ca}^{2+}$ oscillations in cell clusters consisting of cones, RBCs and/or HCs. Our data suggest that gap junctionally-coupled cones, modulated by GABAergic inhibition from HCs, are responsible for generating synchronized, outer retinal activity. We further show that correlated activity between cones and RBCs depends on glutamate transporters expressed by RBCs, suggesting the appearance of atypical, sign-conserving cone-RBC synapses in the remodeled outer $r d 1$ retina.

\section{METHODS AND MATERIALS ANIMALS}

We used adult mice (both genders) at postnatal days (P) 30-60 crossbred from the transgenic HR2.1:TN-XL (Wei et al., 2012) and $C \times 36^{-/-}$(Güldenagel et al., 2001) lines with the $C 3 H / r d 1$ (Bowes et al., 1990) strain. The resulting $r d 1 \times$ HR2.1:TN-XL and $r d 1 \times C \times 36^{-/-}$mice were homozygous for the $r d 1$ allele. We used $n=32 \mathrm{rd} 1 \times \mathrm{HR} 2.1: \mathrm{TN}-\mathrm{XL}$ mice and $n=12 \mathrm{C} 3 \mathrm{H} / \mathrm{rd} 1$ mice; both lines are referred to as " $r d 1$." In addition, we used

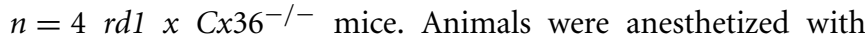
Isoflurane (Baxter, Germany) and killed by cervical dislocation. All procedures were performed in accordance with the law on animal protection (Tierschutzgesetz) issued by the German Federal Government.

\section{TISSUE PREPARATION}

Eyes were enucleated and the retina was isolated in extracellular solution containing (in $\mathrm{mM}$ ): $125 \mathrm{NaCl}, 2.5 \mathrm{KCl}, 2 \mathrm{CaCl}_{2}$, $1 \mathrm{MgCl}_{2}, 1.25 \mathrm{NaH}_{2} \mathrm{PO}_{4}, 26 \mathrm{NaHCO}_{3}$, and 20 glucose, and was maintained at $\mathrm{pH} 7.4$ using carboxygen (95\% $\left.\mathrm{CO}_{2} / 5 \% \mathrm{O}_{2}\right)$. All chemicals were purchased from Sigma-Aldrich (Germany) and Merck (Germany). Since $r d 1$ degeneration progresses with age and retinal eccentricity, recorded fields $(146 \times 110 \mu \mathrm{m})$ were consistently taken within a $\sim 800 \mu \mathrm{m}$ radius from the optic disk. Retinas were incubated in extracellular solution containing $0.27 \mu \mathrm{M}$ Fura-2-AM and 0.1\% Pluronic acid (Invitrogen, Eugene, USA) for $35^{\prime}$ at room temperature (RT), washed, mounted on filter membranes (Millipore, $0.8 \mu \mathrm{m}$ pores) outer retina side up, and transferred to the recording chamber, where the tissue was perfused with carboxygenated medium at $32^{\circ} \mathrm{C}$.

Notably, we were not able to evoke light-driven activity in $r d 1$ mouse retina at $\mathrm{P} 30$ (as measured by $\mathrm{Ca}^{2+}$ imaging in the outer retina and by electrical recordings from ganglion cells; own unpublished data), which is consistent with earlier reports (Stasheff, 2008).

\section{CALCIUM IMAGING AND DATA ANALYSIS}

To record $\mathrm{Ca}^{2+}$ signals simultaneously in different cell types, including cones, RBCs and HCs, we decided to use a synthetic fluorescent $\mathrm{Ca}^{2+}$ indicator that can be loaded non-selectively into the retinal tissue (see above). Because ratiometric measurements are much less sensitive to experimental artifacts (e.g., tissue motion during drug application), we selected the $\mathrm{Ca}^{2+}$ indicator Fura-2 (Grynkiewicz et al., 1985). The genetically encoded $\mathrm{Ca}^{2+}$ sensor TN-XL, which is selectively expressed in cones in the rd1 $x$ HR2.1:TN-XL strain, was here only used for the alignment of recorded with immunostained retinal regions (see Methods, Immunohistochemistry). No differences in activity were detected between cones that contained only Fura-2 (in $\mathrm{C} 3 \mathrm{H} / \mathrm{rd} 1$ animals) and those containing both Fura-2 and TN-XL (in $r d 1 x$ $H R 2.1: T N-X L$ animals), therefore we consider it unlikely that the presence of two $\mathrm{Ca}^{2+}$ buffers critically affected our results.

For Fura-2 $\mathrm{Ca}^{2+}$ imaging, we used an upright fluorescence microscope (BX50WI, Olympus, Germany) equipped with a 40x water immersion objective (LUMPLFLN, 40x/0.80W, $\infty / 0$, Olympus), a polychromator (POLYCHROME II, Till Photonics, Germany) and a CCD camera (TILL Imago X.Y, Till Photonics) with a resolution of $640 \times 480$ pixels $(9.9 \times 9.9 \mu \mathrm{m}$ pixels, with a bit depth of 12), corresponding to a retinal area of $0.25 \times$ $0.25 \mu \mathrm{m}$ per pixel when using the $40 \mathrm{x}$ objective. For all experiments a $2 \times 2$ pixel binning was used. Single-plane two-channel image stacks of the Fura-2 fluorescence in the outer retina were acquired at $10 \mathrm{~Hz}\left(\lambda_{\text {exc }}=340\right.$ and $380 \mathrm{~nm}$; Olympus U-MNU filter set, $30 \mathrm{~ms}$ exposure time) using the TillVision software (v4.0, Till Photonics).

For offline analysis, ratio image stacks were generated by dividing the fluorescence images recorded at the two excitation wavelengths $\left(F_{340 / 380}\right)$. Cells that generated transient $\mathrm{Ca}^{2+}$ events ("active cells") were identified by calculating the standard deviation (SD) image of each stack using ImageJ (http://rsbweb.nih. gov/ij). The SD images also confirmed that the observed activity was almost exclusively restricted to clearly delineated areas of $5-15 \mu \mathrm{m}$ in diameter (cf. Figure 2B, left column), pointing at active cells and arguing against substantial contributions from the surrounding neuropil.

For the subsequent analysis we used custom scripts (MATLAB, The MathWorks, Germany). Active cells were manually encircled by regions of interest (ROIs) to retrieve their $F_{340 / 380}$ (ratio) response trace. We used $F_{340 / 380}$ as a proxy for changes in $\mathrm{Ca}^{2+}$ concentration. Because we were mainly interested in $\mathrm{Ca}^{2+}$ spiking activity (see below) and not in absolute $\mathrm{Ca}^{2+}$ levels, we refrained from calibrating the system. The baseline was determined by averaging $F_{340 / 380}$ trace sections between events across the cells of each recorded field. Only cells with signal-to-noise ratios $\geq 10$ (with the transient amplitude as signal and 1 SD of the baseline fluctuations as "noise") were included in the analysis. From the ratio traces we then determined the mean $\mathrm{Ca}^{2+}$ event frequency $\left(F_{\text {mean }}\right)$ for each cell using a peak detection routine (based on MATLAB's findpeaks routine). In addition, the pairwise Pearson's correlation coefficient index $(\mathrm{Ci})$ was calculated for all cell pairs (using the corrcoef MATLAB routine). Higher event frequencies, for instance as a result of pharmacologically blocking inhibitory feedback (e.g., Figures 6B,E), could, in principle, result in $\mathrm{C} i$ values purely by chance. Therefore, we tested for dependence between $F_{\text {mean }}$ and $C i$ (using linear regression) but did not find any substantial correlations (control: $R^{2}=0.011$; 
with TPMPA/Gabazine, e.g., Figure 6B: $R^{2}=0.009$; with NBQX, Figure 6E: $\left.R^{2}=0.001\right)$. This indicates that $C i$ can indeed be used as a measure for changes in correlated activity between cells. Cell position and type, as well as $F_{\text {mean }}$ and $\mathrm{Ci}$ were then compiled to activity maps of each recorded region. The Wilcoxon signedrank test and the student's $t$-test were used to evaluate drug effects; statistical significance is indicated as ${ }^{*} p \leq 0.05,{ }^{* *} p \leq$ $0.01,{ }^{* * *} p \leq 0.001$, and all parameters are given as mean \pm s.e.m.

Note that we did not detect comparable spontaneous events in cones in retinal whole mounts of HR2.1:TN-XL "wild-type" mice (our unpublished data). This is consistent with the observation of Borowska et al. (2011) that bipolar cells recorded in wild-type mouse whole mounts do not display spontaneous (oscillatory) activity. In contrast, in retinal slices of HR2.1:TN-XL "wildtype" mice we did observe spontaneous events, in particular, when HC feedback inhibition was pharmacologically blocked (see Discussion).

\section{PHARMACOLOGY}

Drugs were bath applied for $10^{\prime}$ and washed out for $20^{\prime}$. We used (in $\mu \mathrm{M})$ : 50 TPMPA $\left(\mathrm{GABA}_{\mathrm{C}}\right.$ receptor antagonist; 1,2,5,6-Tetrahydropyridin-4-yl)met hylphosphinic acid), 10 Gabazine $\left(\mathrm{Gz}, \mathrm{GABA}_{\mathrm{A}}\right.$ receptor antagonist; 6Imino-3-(4-methoxyphenyl)-1 $(6 \mathrm{H})$-pyridazine-butanoic acid hydrobromide), 75 DL-TBOA (glutamate transporter antagonist; DL-threo- $\beta$-Benzyloxyaspartic acid) and 100 CPPG (mGluR6 antagonist; (RS)- $\alpha$-Cyclopropyl-4-phosphonophenylglycine) were purchased from Tocris Bioscience; 1 strychnine (glycine receptor antagonist), 100 Verapamil (L-type voltage-gated calcium channel blocker) and 100 carbenoxolone (CBX, gap

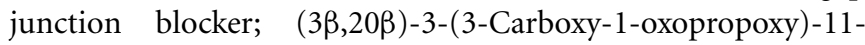
oxoolean-12-en-29-oic acid disodium) were purchased from Sigma-Aldrich; 100 L-AP4 (mGluR6 agonist; L-2-amino-4phosphonobutyric acid) and $20 \mathrm{NBQX}$ (AMPA/kainate-type GluR antagonist; 2,3-Dioxo-6-nitro-1,2,3,4-tetrahydrobenzo[f]quinoxaline-7-sulfonamide) were purchased from Bio Trend. For some experiments, glutamate $(250 \mu \mathrm{M})$ was directly puffed with a glass pipette for $750 \mathrm{~ms}$ onto recorded outer retina neurons using a VC3-8 perfusion system (ALA Scientific Instruments, USA).

\section{IMMUNOHISTOCHEMISTRY}

After $\mathrm{Ca}^{2+}$ imaging, retinas were fixated with $4 \%$ paraformaldehyde (PFA) in extracellular solution for $15^{\prime}$ at RT and washed twice for $20^{\prime}$ in $0.1 \mathrm{M}$ phosphate buffered saline (PBS, in mM: 20 $\mathrm{NaH}_{2} \mathrm{PO}_{4}, 80 \mathrm{Na}_{2} \mathrm{HPO}_{4}, 154 \mathrm{NaCl} ; \mathrm{pH} 7.4$ ) at $4^{\circ} \mathrm{C}$. Retinas were then incubated overnight at $4^{\circ} \mathrm{C}$ in blocking solution containing $0.3 \%$ Triton $\mathrm{X}-100,1 \% \mathrm{BSA}$ and $10 \%$ corresponding normal serum from the host animals used for generating the respective secondary antibodies. Subsequently, retinas were incubated for 1-3 days in primary antibodies (Table 1), washed 6 times for $5^{\prime}$ in PBS and then incubated overnight at $4^{\circ} \mathrm{C}$ in secondary antibodies (1:750, Alexa Fluor conjugates; Invitrogen). After mounting on slides using Vectashield (Vector, Burlingame, CA, USA) the retinas were imaged (stacks with $0.3-0.95 \mu \mathrm{m} \mathrm{z}$-axis steps) using a Zeiss Imager Z1 Apotome (Oberkochen, Germany; Plan-Apochromat 5x/0.16, 20x/0.8 and EC Plan-Neofluar 40x/1.3

Table 1 | Antibodies.

Cone photoreceptors (cones)

Rod bipolar cells (RBCs)

Horizontal cells (HCs)

Connexin36

EAAT5

Table listing antibodies for immunolabeling experiments.

oil; filter set \#38 for Alexa Fluor 488, \#10 for Alexa Fluor 568, \#50 for Alexa Fluor 633, \#49 for DAPI). Fixated vertical retina sections $(22 \mu \mathrm{m})$ were incubated overnight in primary antibodies, for $1 \mathrm{~h}$ in secondary antibodies and subsequently imaged as described above (stacks $\mathrm{w} / 0.32 \mu \mathrm{m}$ z-axis steps).

In the $r d 1 \times H R 2.1: T N-X L$ mouse line, in which cones are fluorescently labeled by TN-XL, identification of cell types and alignment of $\mathrm{Ca}^{2+}$ imaged regions with the tissue after immunostaining was greatly facilitated. Directly after $\mathrm{Ca}^{2+}$ imaging, a picture of the recorded region was taken to visualize TN-XLexpressing cones (using the U-MSWG Olympus filter set). The pattern of TN-XL-positive cones was then used as landmark to find the recorded region on the immunostained retina and to determine active cell types by overlaying Fura- 2 image, TN-XL image, and the images of the immunostained retina. We observed little shrinkage of the retinal tissue (5-7\% compared to the living retina); in any case, because that shrinkage was homogenous we were able to register pictures from live-imaging and immunostained material reliably (in 51 of 58 cases; for examples, see Figures 1C, 7A). In the $r d 1 \times H R 2.1: T N-X L$ line, TN-XL labeling in cones was intensified using antibodies against GFP (which also works for labeling TN-XL). In experiments using the $C 3 H / r d 1$ and $r d 1 \times C \times 36^{-/-}$lines we identified cones using recoverin staining (Lambrecht and Koch, 1992). To identify Fura-2 labeled noncone cell types, we stained the fixed tissue for PKC $\alpha$ to label RBCs (Berrebi et al., 1991) and for calbindin to label HCs (Pasteels et al., 1990). The Fura-2 labeled cells that were not stained by these two antibodies likely represented cone bipolar cells.

\section{RESULTS \\ NEURONS IN THE OUTER rd1 RETINA DISPLAY SPONTANEOUS ACTIVITY}

At the adult age of mice when $\mathrm{Ca}^{2+}$ recordings were performed, cone somata form a single irregular cell layer in the outer $r d 1$ mouse retina (Figures 1A,C) (Carter-Dawson et al., 1978; Jimenez et al., 1996). Therefore, all neuron types of the rd1 outer retina (Figure 1B, cones, HCs and bipolar cells), are accessible from the distal retinal surface and their activity can be recorded in the Fura-2 loaded $r d 1$ retinal wholemount using $\mathrm{Ca}^{2+}$ imaging (Figure 1C). Subsequent to the $\mathrm{Ca}^{2+}$ imaging, we performed immunocytochemistry to identify cones, RBCs and 

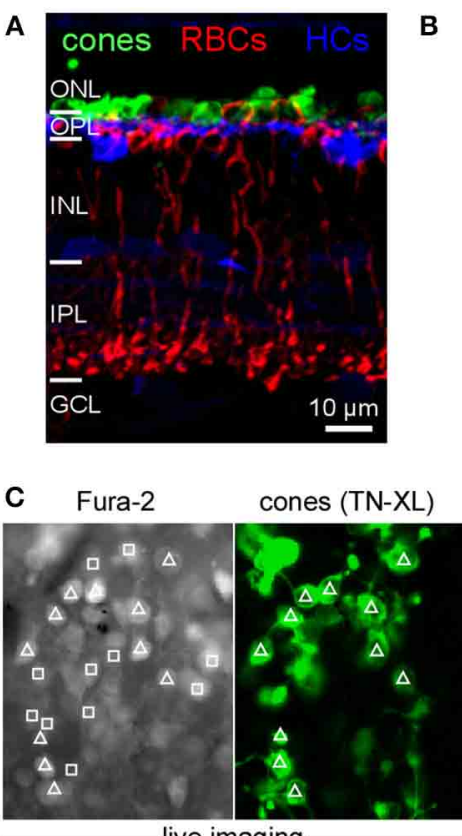

-live imaging

B

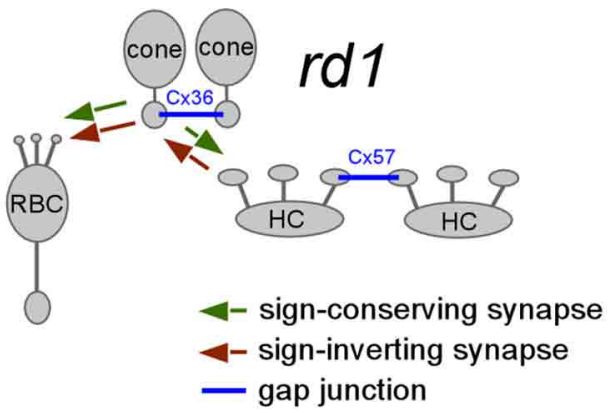

cones $(\mathrm{TN}-\mathrm{XL})$

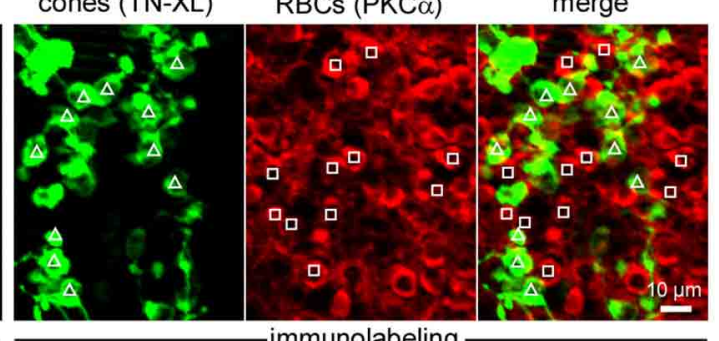

FIGURE 1 | Cell type identification following $\mathrm{Ca}^{2+}$ imaging in the outer retina of $\boldsymbol{r d 1}$ mice. (A) Vertical section of a P35 rd1 retina immunostained for $\mathrm{TN}-\mathrm{XL}$ (cones), PKC $\alpha$ (RBCs) and calbindin (HCs). (B) Drawing illustrating sign-conserving (green), sign-inverting (red), and electrical (blue) synaptic interactions in the outer rd1 retina. For simplicity, interactions between $\mathrm{HCs}$ and RBCs are not shown. (C) From left to right: Fura-2-labeled neurons in outer retina in living P35 rd1 wholemount retina
( $F_{340}$ channel), cones expressing TN-XL (live image taken at the same retinal location as Fura-2 image; triangles indicate cones), immunolabeling of same wholemount retina subsequent to the $\mathrm{Ca}^{2+}$ imaging experiment showing cones stained for TN-XL and PKC $\alpha$-stained RBCs (red, squares). $(\mathrm{ONL}$, outer nuclear layer; OPL, outer plexiform layer; INL, inner nuclear layer; IPL, inner plexiform layer; $\mathrm{GCL}$, ganglion cell layer; $\mathrm{RBC}$, rod bipolar cell; HC, horizontal cell).
HCs (Figures 1C, 7A). In adult $r d 1$ mice, up to $35 \%$ of all Fura2 loaded cells in the outer retina were spontaneously active and displayed transient $\mathrm{Ca}^{2+}$ events (Figures 2A,B; cones: $\tau=112 \pm$ $182 \mathrm{~ms}, n=30$; RBCs: $\tau=177 \pm 173 \mathrm{~ms}, n=22$; unidentified: $\tau$ $=135 \pm 152 \mathrm{~ms}, n=15)$. While the mean frequency $\left(F_{\text {mean }}\right)$ for individual cells reached up to $3 \mathrm{~Hz}$, the studied types/groups of cells were typically dominated by frequencies below $1 \mathrm{~Hz}$ (cones: $F_{\text {mean }}=0.65 \pm 0.35 \mathrm{~Hz}, n=902$; RBCs: $F_{\text {mean }}=0.38 \pm 0.42 \mathrm{~Hz}$, $n=766$; HCs: $F_{\text {mean }}=0.26 \pm 0.15 \mathrm{~Hz}, n=43$; unidentified: $F_{\text {mean }}=0.57 \pm 0.61 \mathrm{~Hz}, n=94$; see also Figure 2E).

Of each recorded field we generated an "activity map" that provided information about cell type, position, and $F_{\text {mean }}$ of every active, identified cell (Figure 2C). Cells analyzed in $n=25 r d 1$ retinas included $50.1 \%$ cones, $42.6 \%$ RBCs, $2.3 \% \mathrm{HCs}$, as well as $5 \%$ unidentified cells. The latter consisted of cells that could not be clearly assigned to stained counterparts and presumably also contained one or more types of cone bipolar cell. Because they were infrequent and likely a heterogeneous group, we did not study them further.

\section{SPONTANEOUS $\mathrm{Ca}^{2+}$ TRANSIENTS IN THE OUTER rd1 RETINA RELY ON VOLTAGE-GATED $\mathrm{Ca}^{2+}$ CHANNELS}

To assess whether spontaneous $\mathrm{Ca}^{2+}$ transients in $r d 1$ cones depend on activation of L-type voltage-gated $\mathrm{Ca}^{2+}$ channels (VGCCs), which are present in cones (Nachman-Clewner et al., 1999), we applied the specific antagonist verapamil. Blocking
L-type VGCCs eliminated spontaneous cone activity (Figure 2D, left), suggesting that fluctuations of the cone membrane potential that activate VGGCs are required for the observed cone $\mathrm{Ca}^{2+}$ transients. Verapamil also eliminated spontaneous RBC activity (Figure 2D, right), likely as a result of both the blockade of Ltype VGCCs in RBCs (Protti and Llano, 1998) and the reduction of glutamatergic drive from cones. Together these results suggest that the measured $\mathrm{Ca}^{2+}$ transients reflect electrical neuronal activity in the outer $r d 1$ retina. It is possible that the frequency of spontaneous $\mathrm{Ca}^{2+}$ events represents an underestimate of the cells' electrical activity, as we can detect only membrane potential fluctuations that are large enough to trigger VGGCs. Furthermore, it is possible that $\mathrm{Ca}^{2+}$ release from internal stores contributed to the measured signals (Wei et al., 2012). In principle, spontaneous activity in the inner $r d 1$ retina (Borowska et al., 2011) may also contribute to outer retinal activity i.e., via glycinergic and/or GABAergic input from amacrine cells (ACs) to BC terminals or possibly via GABAergic interplexiform cells to the outer plexiform layer (OPL). However, it is unlikely that the observed outer retinal activity relied on such input, because blocking glycine receptors had no effect while GABA receptor antagonists even enhanced that activity (Table 2, cf. also Figure 6B). Additionally, multi-electrode recordings in the $r d 1$ retina (Ye and Goo, 2007) showed that while spiking activity is blocked by TTX, a slow $(\sim 3.2 \mathrm{~Hz})$ component persists. Because TTX was demonstrated to block inner retinal activity (Trenholm et al., 2012), the finding 

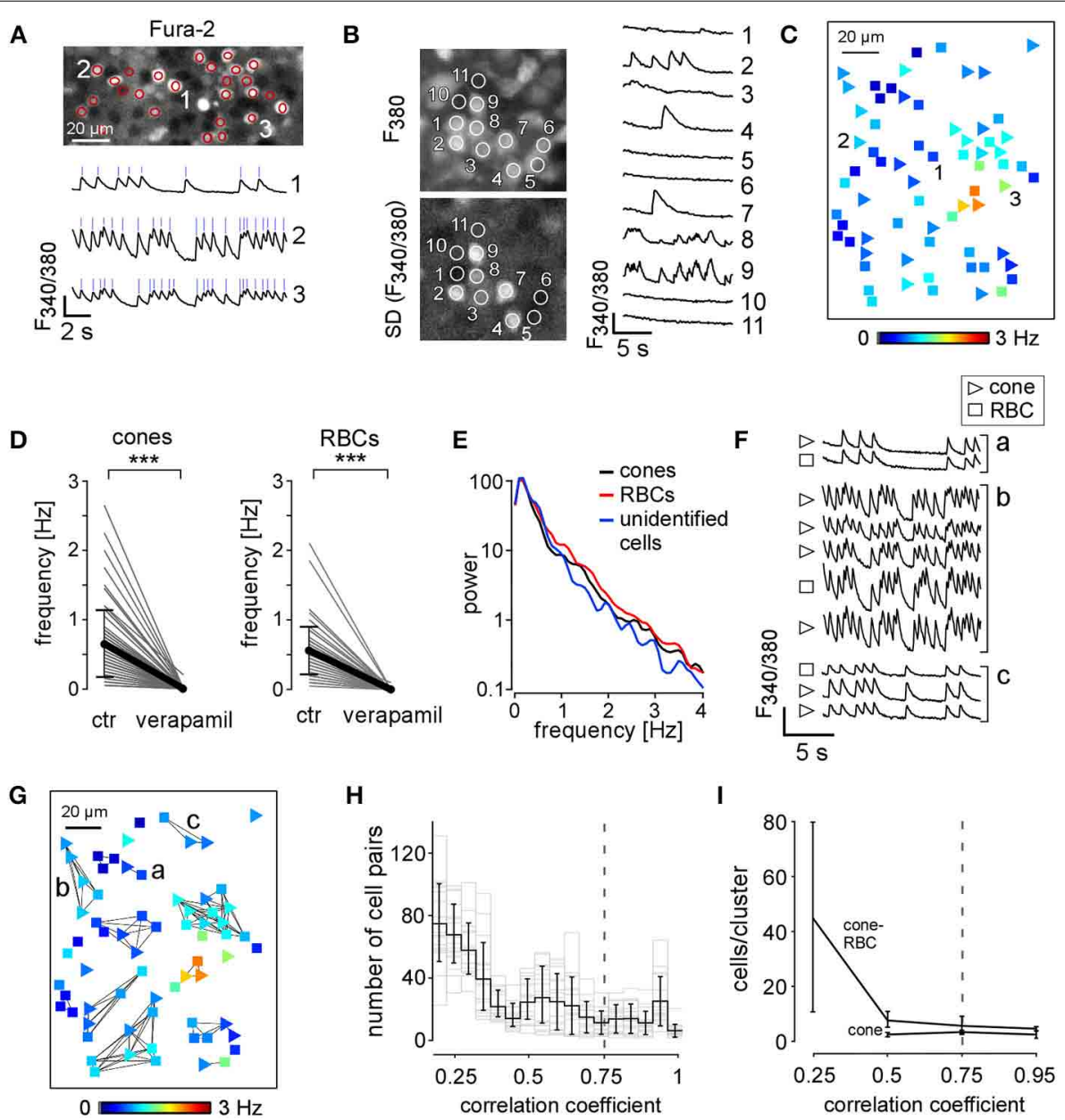

FIGURE 2 | Spontaneous activity in the outer retina of $r d 1$ mice. (A) Fura-2-labeled $r d 1$ retina wholemount (SD image of $F_{340 / 380}$ ratio) with active cells encircled (regions of interest, $\mathrm{ROIs}$ ) and exemplary $\mathrm{Ca}^{2+}$ traces (ROls 1-3; blue ticks mark peaks of $\mathrm{Ca}^{2+}$ transients used to determine $\left.F_{\text {mean }}\right)$. (B) left: wholemount with ROls placed on different regions: Fura-2-labeled cells, ROls 1-9; active cells, ROls 2-4, 7-9; unlabeled cells/space, ROls 10,11 (top: averaged time series, $F_{380}$ channel; bottom: $S D$ image of $F_{340 / 380}$ ratio, same time series). Right: corresponding $\mathrm{Ca}^{2+}$ traces. (C) Activity map showing distribution of mean frequency ( $F_{\text {mean }}$, color-coded) of spontaneous $\mathrm{Ca}^{2+}$ transients in cones (triangles) and RBCs (squares). (D) Verapamil abolishes spontaneous activityin cones (left) and RBCs (right). (E) Power spectrum of the activity in cones (black, $n=81$ ), RBCs (red, $n=108$ ), and unidentified cells (blue, $n=4$ ); data from 3 experiments. (F) Exemplary $\mathrm{Ca}^{2+}$ traces of cells exhibiting synchronous activity (clusters a-c in G). (G) Activity map showing clusters with synchronous $\mathrm{Ca}^{2+}$ transients (cross-correlation coefficient $\geq 0.75$ indicated by lines). (H) Histogram showing the distribution of cross correlations between measured cell pairs ( $n=19$ retinas) for different correlation coefficients. Gray dashed line indicates correlation coefficient $\geq 0.75$ used for our analysis. (I) Plot showing cluster size (cells/cluster) of cone-only and cone-RBC clusters for different correlation coefficients. Cluster size did not vary for correlation coefficients $\geq 0.5$. All error bars indicate s.e.m. by Ye and Goo (2007) points at the presence of oscillatory network in the $r d 1$ retina that does not depend on inner retinal activity.

\section{CLUSTERS OF SYNCHRONOUS ACTIVITY IN THE rd1 OUTER RETINA}

Calcium transients were often synchronized in neighboring cells, forming clusters of correlated oscillatory activity (Figure 2F). Such correlated activity between cells is indicated in activity maps by connecting lines visualizing synchronized cell clusters (Figure 2G). While already correlation coefficient thresholds $\geq$ 0.5 were sufficient to reliably identify clusters (Figures $\mathbf{2 H}, \mathbf{I}$, cf. also respective histograms in Figures 5E, 6H,I for different pharmacological conditions), we used a more "conservative" threshold of 0.75 to focus on the strong interactions between cells.
Most activity clusters comprised both cones and RBCs. Under control conditions, we detected in $22 \mathrm{rd} 1$ retinas a total of 144 clusters, including 92 cone-RBC clusters ( $5.5 \pm 3.4$ cells/cluster), 31 cone-only clusters $(3.0 \pm 1.1$ cells/cluster, see Table 3$)$ and 21 $\mathrm{RBC}$-only clusters $(2.2 \pm 0.4$ cells/cluster $)$. It is likely that the relatively rare $\mathrm{RBC}$-only clusters actually were cone-RBC clusters for which the contributing cones could not be identified-for instance because they were located outside the recorded area (see, for example, lower left cluster in Figure 2G). Therefore, we did not include RBC-only clusters in our analysis. We also found synchronous activity between cones, RBCs and unidentified cells (data not shown). Because unidentified cells were rather infrequent and represent a heterogeneous group (see above), we 
Table 2 | Pharmacology of spontaneous activity in rd1 outer retinal neurons.

\begin{tabular}{|c|c|c|c|c|}
\hline $\begin{array}{l}\text { Cell } \\
\text { type }\end{array}$ & $\begin{array}{c}\text { Number of } \\
\text { cells }\end{array}$ & $\begin{array}{l}\text { Control } \\
\left(\boldsymbol{F}_{\text {mean }}\right)\end{array}$ & Drug & Wash-out \\
\hline \multicolumn{5}{|c|}{ rd1, CONTROL; $n=25$ RETINAS; $n=1711$ CELLS } \\
\hline Cones & $n=902$ & $0.65 \pm 0.35$ & - & - \\
\hline RBCs & $n=766$ & $0.38 \pm 0.42$ & - & - \\
\hline $\mathrm{HCs}$ & $n=43$ & $0.26 \pm 0.15$ & - & - \\
\hline \multicolumn{5}{|c|}{$r d 1$, VERAPAMIL; $n=3$ RETINAS; $n=154$ CELLS } \\
\hline Cones & $n=85$ & $0.65 \pm 0.47$ & $0.00 \pm 0.02 * * *$ & $0.20 \pm 0.46 * * *$ \\
\hline RBCs & $n=69$ & $0.56 \pm 0.35$ & $0.00 \pm 0.01 * * *$ & $0.08 \pm 0.21 * * *$ \\
\hline \multicolumn{5}{|c|}{$r d 1$, STRYCHNINE; $n=3$ RETINAS; $n=160$ CELLS } \\
\hline Cones & $n=101$ & $0.54 \pm 0.44$ & $0.55 \pm 0.33$ & $0.51 \pm 0.38$ \\
\hline $\mathrm{RBCs}$ & $n=59$ & $0.50 \pm 0.32$ & $0.48 \pm 0.34$ & $0.52 \pm 0.30$ \\
\hline \multicolumn{5}{|c|}{$r d 1$, TPMPA + Gz + TBOA; $n=6$ RETINAS; $n=1128$ CELLS } \\
\hline & & & $\mathrm{TPMPA}+\mathrm{Gz}$ & + TBOA \\
\hline Cones & $n=669$ & $0.10 \pm 0.21$ & $0.63 \pm 0.58 * * *$ & $1.04 \pm 0.63^{* * *}$ \\
\hline RBCs & $n=459$ & $0.08 \pm 0.21$ & $0.62 \pm 0.52 * * *$ & $0.41 \pm 0.38^{* * *}$ \\
\hline \multicolumn{5}{|c|}{$r d 1$, L-AP4; $n=5$ RETINAS; $n=293$ CELLS } \\
\hline Cones & $n=122$ & $0.24 \pm 0.43$ & $0.47 \pm 0.60 * * *$ & $0.44 \pm 0.50$ \\
\hline RBCs & $n=171$ & $0.55 \pm 0.35$ & $0.11 \pm 0.23 * * *$ & $0.15 \pm 0.35$ \\
\hline \multicolumn{5}{|c|}{$r d 1$, CPPG; $n=5$ RETINAS; $n=344$ CELLS } \\
\hline Cones & $n=197$ & $0.44 \pm 0.38$ & $0.95 \pm 0.66^{* * *}$ & $0.99 \pm 0.75$ \\
\hline RBCs & $n=147$ & $0.60 \pm 0.43$ & $1.07 \pm 0.60 * * *$ & $1.05 \pm 0.72$ \\
\hline \multicolumn{5}{|c|}{ rd1 $\times C \times 36^{-1-} ; n=4$ RETINAS; $n=265$ CELLS } \\
\hline Cones & $n=153$ & $0.53 \pm 0.39$ & - & - \\
\hline RBCs & $n=112$ & $0.51 \pm 0.42$ & - & - \\
\hline \multicolumn{5}{|c|}{$r d 1$, TPMPA+Gz; $n=6$ RETINAS; $n=499$ CELLS } \\
\hline Cones & $n=278$ & $0.22 \pm 0.35$ & $0.82 \pm 0.48^{* * *}$ & $1.04 \pm 0.70 * * *$ \\
\hline RBCs & $n=221$ & $0.26 \pm 0.37$ & $0.92 \pm 0.53^{* * *}$ & $0.99 \pm 0.58 * *$ \\
\hline \multicolumn{5}{|c|}{ rd1, NBOX; $n=3$ RETINAS; $n=148$ CELLS } \\
\hline Cones & $n=85$ & $0.27 \pm 0.47$ & $1.14 \pm 0.69 * * *$ & $0.61 \pm 0.40 * * *$ \\
\hline RBCs & $n=63$ & $0.40 \pm 0.47$ & $1.18 \pm 0.62 * * *$ & $0.5 \pm 0.36 * * *$ \\
\hline \multicolumn{5}{|c|}{$r d 1$, CBX; $n=3$ RETINAS; $n=43$ HCs } \\
\hline $\mathrm{HCs}$ & $n=43$ & $0.26 \pm 0.15$ & $0.02 \pm 0.11 * * *$ & - \\
\hline
\end{tabular}

Table showing mean $\mathrm{Ca}^{2+}$ event frequencies (in $\mathrm{Hz}$ ) for cones, rod bipolar cells (RBCS) and horizontal cells (HCS) for control condition, during drug application and after wash-out. Statistical significance is indicated as ${ }^{* *} p<0.01$, and ${ }^{* * *}<0.001$ (control vs. drug or wash-out conditions). Gz, Gabazine; CBX, carbenoxolone.

excluded this group from the cluster analysis. In addition, in some experiments we found synchronous oscillatory activity among HCs and between HCs and cones (Figure 7).

\section{CONE AND ROD BIPOLAR CELLS ACTIVITY IS SYNCHRONIZED BY EAAT5 RECEPTORS}

In the wild-type mammalian retina, ON bipolar cells, including RBCs, integrate glutamatergic photoreceptor output using the sign-inverting mGluR6 (Nakajima et al., 1993; Pang et al., 2010). Thus, activity in photoreceptors and ON bipolar cells is expected to be negatively correlated. Our finding of positively correlated activity between cones and RBCs in the $r d 1$ retina was therefore surprising. It suggests that previously described ectopic synapses between the bulb-like neurites sprouting from cones and
RBC somata (Figure 3; see also Peng et al., 2000; Cuenca et al., 2004) are functional and sign-conserving. A potential alternative explanation is that fluorescence signals from neighboring labeled cells combined into one ROI caused false-positive correlations. However, we think that the contribution of such "bleeding-in" was marginal (see Figure 2B and Methods): in the $\mathrm{x}-\mathrm{y}$ plane $\mathrm{Ca}^{2+}$ transients were localized to defined cell-sized areas and, thus, mostly well-separated from their active neighbors, and along the z-axis, we typically saw little "stacking" of active cells.

A possible biological explanation for sign-conserving synaptic transmission between $r d 1$ cones and RBCs could be degenerationinduced expression of AMPA/kainate-type GluRs on RBCs (Chua et al., 2009). However, this seems unlikely, because application of NBQX, an AMPA/kainate-type GluR antagonist, increased the activity of RBCs and the number of cone-RBC clusters (see Tables 2, 3; cf. also Figures 6E,F), likely due to a reduction of inhibition by HCs (for discussion, see Thoreson and Mangel, 2012), which possess AMPA/kainate-type GluRs (Schubert et al., 2006; Ströh et al., 2013).

An alternative explanation involves glutamate transporters and a transmission pathway that has been described in fish bipolar cells (Grant and Dowling, 1995). In wild-type mice, the glutamate transporter EAAT5 is present on both RBC axon terminal and soma (Wersinger et al., 2006). EAAT5 exhibits a $\mathrm{Cl}^{-}$conductance that is activated by glutamate binding but independent from the actual glutamate transport across the membrane (Fairman et al., 1995; Arriza et al., 1997). Because the $\mathrm{Cl}^{-}$reversal potential in the RBC dendro-somatic compartment is more positive than the resting potential (Billups and Attwell, 2002; Varela et al., 2005), activation of the EAAT5 $\mathrm{Cl}^{-}$conductance by glutamate released from the cones is expected to trigger $\mathrm{Cl}^{-}$efflux from the RBCs. The bipolar cells would depolarize, leading to activation of VGCCs (Protti and Llano, 1998) and, consequently synchronize $\mathrm{Ca}^{2+}$ transients in cones and RBCs.

To test this hypothesis, we first confirmed the presence of EAAT5 on $r d 1$ cones and RBCs using immunocytochemistry (Figures 4A-C). Then we measured the effect of the general glutamate transporter antagonist TBOA on the synchronized $\mathrm{Ca}^{2+}$ activity between cones and RBCs (Figure 4D). As predicted by our hypothesis, TBOA significantly reduced the numbers of cone-RBC clusters (Figure 4E; for this and further statistics, see Table 3), likely by blocking EAAT5. Because of the comparably low number of clusters that we typically found under control conditions, we also evaluated the effect of TBOA on tissue in which we first enhanced the activity (and thereby the cluster number). Blocking $\mathrm{GABA}_{\mathrm{A} / \mathrm{C}}$ receptors with the antagonists Gabazine/TPMPA increased spontaneous activity and enhanced synchronous activity between cones and RBCs (Figures 4F,G; see Tables 2, 3). This observation is consistent with inhibitory GABAergic feedback (see Horizontal cells attenuate activity in the $r d 1$ outer retina), as $r d 1$ cones (Pattnaik et al., 2000) express GABA receptors-notably, in contrast to wild-type cones (Kemmler et al., 2014). To study the TBOA effect on enhanced $r d 1$ activity, we first applied Gabazine/TPMPA and then added TBOA. Co-application of TBOA reduced RBC activity (Figure 4 F) but at the same time increased activity in cones (Table 2). The opposite effect on the two cell types is not surprising, because- other 
Table 3 | Analysis of cluster activity in the outer $r d 1$ retina.

\begin{tabular}{|c|c|c|c|c|c|}
\hline Cluster type & \multicolumn{2}{|c|}{ Clusters/Field (\# Clusters total) } & \multicolumn{3}{|c|}{ Cells/Cluster } \\
\hline Cone-only & $1.4 \pm 1(31)$ & $\mathrm{n} / \mathrm{a}$ & \multicolumn{2}{|c|}{$3 \pm 1.1$} & $\mathrm{n} / \mathrm{a}$ \\
\hline Cone-RBC & $4.2 \pm 1.7(92)$ & $\mathrm{n} / \mathrm{a}$ & \multicolumn{2}{|c|}{$5.5 \pm 3.4$} & $\mathrm{n} / \mathrm{a}$ \\
\hline $\mathrm{HC}-\mathrm{HC}$ & $1 \pm 0(3)$ & $\mathrm{n} / \mathrm{a}$ & \multicolumn{2}{|c|}{$14.3 \pm 4.1$} & $\mathrm{n} / \mathrm{a}$ \\
\hline Cone-RBC & $3.75 \pm 1.7(15)$ & $1 \pm 1.4^{*}(4)$ & \multicolumn{2}{|c|}{$3.7 \pm 1.8$} & $2.5 \pm 0.6$ \\
\hline \multicolumn{6}{|c|}{$r d 1$, TPMPA + Gz + TBOA; $n=6$ RETINAS; CONES $n=669$, RBCs $n=459$} \\
\hline & TPMPA + Gz & TPMPA + Gz + TBOA & Control & $\mathrm{TPMA}+\mathrm{Gz}$ & TPMPA + Gz + TBOA \\
\hline Cone-only & $2.3 \pm 1.6(14)$ & $3.3 \pm 2.8(20)$ & $2.4 \pm 1.3$ & $2 \pm 0.8$ & $2.2 \pm 1.1$ \\
\hline \multicolumn{6}{|c|}{ rd1, CPPG; $n=5$ RETINAS; CONES $n=197$, RBCs $n=147$} \\
\hline Cone-only & $1.6 \pm 1.2(8)$ & $4.2 \pm 1.3^{* *}(21)$ & \multicolumn{2}{|c|}{$2.8 \pm 0.9$} & $3.1 \pm 1.2$ \\
\hline Cone-RBC & $5 \pm 1.6(25)$ & $1.2 \pm 0.9 * *(6)$ & \multicolumn{2}{|c|}{$5.6 \pm 3.3$} & $3.2 \pm 1.2$ \\
\hline \multicolumn{6}{|c|}{$r d 1$, TPMPA + Gz + CBX; $n=3$ RETINAS; CONES $n=193$, RBCs $n=113$} \\
\hline & TPMPA + Gz & TPMPA + Gz + CBX & Control & TPMA + Gz & TPMPA + Gz + CBX \\
\hline Cone-only & $3.7 \pm 1.2(11)$ & $0 \pm 0 * * *(0)$ & $3.1 \pm 1.3$ & $3.2 \pm 1.9$ & $\mathrm{n} / \mathrm{a}$ \\
\hline Cone-RBC & $3.5 \pm 1.8(18)$ & $0.3 \pm 0.6 * *(1)$ & $4.3 \pm 1.8$ & $4.9 \pm 2.3$ & $2 \pm 0$ \\
\hline \multicolumn{6}{|c|}{ rd1 $\times C \times 36^{-/-} ; n=4$ RETINAS (7 RECORDINGS); CONES $n=273$, RBCs $n=216$} \\
\hline Cone-only & $0.43 \pm 0.53(3)$ & $\mathrm{n} / \mathrm{a}$ & \multicolumn{2}{|c|}{$2 \pm 0$} & $\mathrm{n} / \mathrm{a}$ \\
\hline$r d 1, \mathrm{CBX} ; n=$ & RETINAS; HCs $n=43$ & & & & \\
\hline $\mathrm{HC}-\mathrm{HC}$ & $1 \pm 0(3)$ & $0 \pm 0 * * *(0)$ & 14.3 & & $\mathrm{n} / \mathrm{a}$ \\
\hline
\end{tabular}

Table showing cluster activity (clusters/field and cells/cluster) for cone-only clusters, cone-RBC clusters and HC-HC clusters for control and drug condition. Statistical significance is indicated as ${ }^{*} p<0.05,{ }^{* *} p<0.01$, and ${ }^{* *}<0.001$ (control vs. drug condition). Gz, Gabazine; CBX, carbenoxolone.

than in RBCs (see above)—cone $\mathrm{Cl}^{-}$concentration is low and, thus, the $\mathrm{Cl}^{-}$reversal potential is more negative than their resting potential (Picaud et al., 1995). Hence, blockage of a transportermediated $\mathrm{Cl}^{-}$inward current should lead to cone disinhibition. In line with the previous experiments (Figure 4E), TBOA strongly reduced the number of cone-RBC clusters also in the presence of GABA receptor antagonists (Figure 4G, Table 3). At the same time, the number of cone-only clusters increased but not significantly, which likely reflects "decoupling" of cone-RBC connections but may also partially explained by the increased number of active cones, that is, more cone-only clusters reached our correlation threshold.

The results so far predict that activation of glutamate transporters on $r d 1$ RBCs should cause depolarization due to their high intracellular $\mathrm{Cl}^{-}$concentration and $\mathrm{Ca}^{2+}$ responses due to VGCC activation. To test this prediction, we puffed glutamate directly onto RBCs and found that glutamate evoked large $\mathrm{Ca}^{2+}$ transients (Figures $4 \mathbf{H}, \mathbf{J}$ ). Puffing glutamate in the presence of TBOA (Figures $4 \mathbf{H}, \mathbf{I}$ ) or verapamil (Figures 4J,K) failed to evoke responses, suggesting that indeed glutamate transportermediated depolarization and downstream activation of VGCCs underlie $\mathrm{Ca}^{2+}$ transients in RBCs. The possibility that glutamate acted on HCs which, in turn, synaptically excited RBCs, can be excluded: both the application of NBQX (blocking HC input) and of TPMPA $+\mathrm{Gz}$ (blocking potential RBC input from HCs) increased spontaneous activity in RBCs (see also below), indicating that there is no direct (GABAergic) excitatory drive from HCs to RBCs. Thus, our data indicate that correlated cone-RBC 


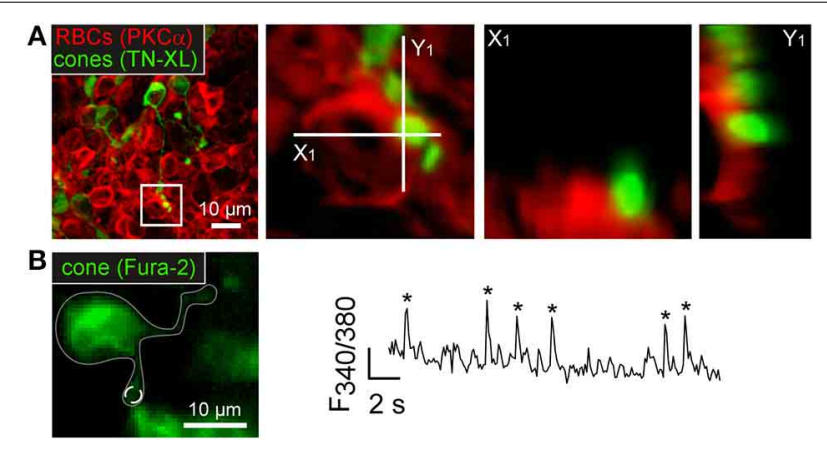

FIGURE 3 | Degenerating cones sprout and contact rod bipolar cells in rd1 mice. (A) Immunolabeled cones ( $\mathrm{TN}-\mathrm{XL}$, green) and $\mathrm{RBCs}$ ( $\mathrm{PKC} \alpha$, red) in P35 rd1 retina. Higher magnification view of boxed area showing a RBC soma contacted by a cone neurite. X-images show horizontal and Y-images vertical single-plane sections of higher magnification view. (B) Left: Fura-2-and TN-XL-labeled cone (gray line outlines cone; dashed white circle indicates $\mathrm{ROI}$ ). Right: $\mathrm{Ca}^{2+}$ trace $\left(F_{340 / 380}\right.$ ratio) with transients (indicated by asterisks) recorded in $\mathrm{ROI}$ in cone process (white dashed circle).

activity is based on sign-conserving ectopic synapses between cones and RBCs and mediated, at least partially, by glutamate transporters (likely EAAT5).

mGLUR MODULATES SYNAPTIC ACTIVITY BETWEEN CONES AND RBCs

Is there a role for mGluR6, which mediates transmission from rods to RBCs in wild-type mammalian retina (Nakajima et al., 1993), also in $r d 1$ ? To test this, we bath-applied the group III mGluR agonist L-AP4 and antagonist CPPG and measured spontaneous activity. We found that L-AP4 decreased RBC activity, whereas CPPG led to an increase in RBC activity (Figures $4 \mathbf{L}, \mathbf{M}$, Table 2). This result is consistent with the "normal," signinverting mGluR6 signaling: L-AP4 mimics glutamate binding to mGluR6, leading to the closure of downstream TRPM1 cation channels, whereas CPPG mimics glutamate unbinding from mGluR6, leading to the opening of TRPM1 channels (Morgans et al., 2009). During L-AP4 or CPPG application, cone-RBC clusters were almost absent and the number of cone-only clusters increased significantly (Figures $4 \mathbf{N}, \mathbf{O}$ ). This suggests that: (i) $r d 1$ RBCs still express functional mGluR6, although the transmission from the cones appears to be dominantly mediated by glutamate transporters, as we find cone-RBC activity to be positively and not negatively correlated (see previous section). (ii) Hyperpolarizing or depolarizing the $r d 1$ RBCs by modulation of the TRPM1 channels via the activation or blockade of mGluR6, respectively, appears to "clamp" the cells' membrane potential and thereby effectively "decouples" RBCs from cone input-restricting synchronous activity largely to cone-only clusters.

In addition to mGluR6 on RBCs, there is also at least one other group III mGluR in the OPL that is sensitive to L-AP4 and CPPG: the mGluR8 auto-receptor on photoreceptors (Koulen et al., 1999). Other than for RBCs, not only the antagonist CPPG significantly increased the frequency of cone $\mathrm{Ca}^{2+}$ transients, but also the agonist L-AP4 (see Table 2). However, the relative cone $\mathrm{Ca}^{2+}$ level (as reflected by the mean baseline ratio) increased with CPPG (control: $1.3 \pm 0.4$, CPPG: $1.7 \pm 0.6, n=197, p \leq 0.001$ ) but decreased with L-AP4 (control: $1.5 \pm 0.6$, L-AP4: $1.2 \pm$ $0.6, n=122, p \leq 0.001$ ), consistent with mGluR8 auto-receptors modulating the cone's basal $\mathrm{Ca}^{2+}$ level (Koulen et al., 1999). Why cones became more "spiky" despite a reduction in basal $\mathrm{Ca}^{2+}$ level during L-AP4 application remains to be investigated.

Taken together, glutamate released from $r d 1$ cones modulates both the activity of cones (auto-reception via mGluR8, EAATs) and RBCs (via mGluR6, EAATs), nevertheless, transmission from cones to RBCs appears to be dominated by sign-conserving glutamate transporter activation.

\section{DISRUPTING ELECTRICAL CONE COUPLING ELIMINATES SYNCHRONOUS ACTIVITY IN THE OUTER rd1 RETINA}

The great majority of the clusters included cones, indicating that spontaneous activity may be initially generated in the "islandlike" small groups of cones and is then synaptically spread to RBCs and HCs. But what synchronizes spontaneous activity in cones in the first place? Cones are electrically coupled via gap junctions formed by connexin36 (Cx36) (Feigenspan et al., 2004). In the $r d 1$ retina, neuritic protrusions of remnant cones express Cx36 (Figure 5A), suggesting that clustered cones remain electrically coupled during degeneration. To uncouple the cone network, we used the gap junction blocker carbenoxolone $(\mathrm{CBX})$. Since $\mathrm{CBX}$ is non-selective and therefore also uncouples the gap junctions of the HC network, we first reduced $\mathrm{HC}$ feedback using GABA receptor blockers and then co-applied CBX (Figures 5B,C). Note that CBX may also contribute to the reduction of $\mathrm{HC}$-cone feedback by eliminating the alternative hemichannel-mediated ephaptic HC feedback pathway (Kamermans and Fahrenfort, 2004). We found the number of cone-only and cone-RBC clusters was significantly decreased by adding CBX (Figures 5D,E, Table 3), suggesting that electrical cone coupling is important for synchronizing $r d 1$ activity.

Because CBX acts non-selectively on gap junctions and hemichannels, and has potential side-effects on VGCCs (Vessey et al., 2004), we also used $r d 1$ mice crossbred with a Cx36 knockout line $\left(r d 1 \times C \times 36^{-/-}\right)$(Figure 5F), in which photoreceptor coupling is eliminated. While the overall activity in cones and RBCs was not altered in the $r d 1 \times C \times 36^{-/-}$retina (Figure 5G, Table 2), the number of cone-only and cone-RBC clusters (Figure $5 \mathbf{H}$ ) and the number of cells per cone-RBC clusters (Figure 5I, Table 3) were significantly lower. This supports our interpretation of the CBX effect that electrical coupling between cones is crucial for synchronizing activity clusters in the outer $r d 1$ retina. That the results in the $r d 1 \times C \times 36^{-/-}$retina are very similar to those with $\mathrm{CBX}$ also argues against a substantial suppressive effect on VGCCs at the CBX concentrations we used.

\section{HORIZONTAL CELLS ATTENUATE ACTIVITY IN THE rd1 OUTER RETINA}

Mouse horizontal cells receive glutamatergic input from cones via AMPA/kainate-type GluRs (Schubert et al., 2006; Ströh et al., 2013). In turn, they provide feedback and feedforward input to photoreceptors and bipolar cells, respectively, via diverse synaptic mechanisms. These mechanisms include GABAergic, ephaptic and $\mathrm{pH}$-mediated feedback (reviewed in Thoreson and Mangel, 2012). In the $r d 1$ retina, HC neurites sprout vertically toward the outer and inner retina (Rossi et al., 2003) and, thus, it is likely that 


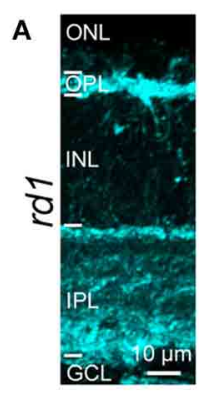

E

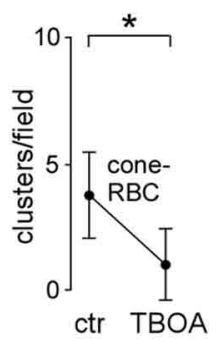

H

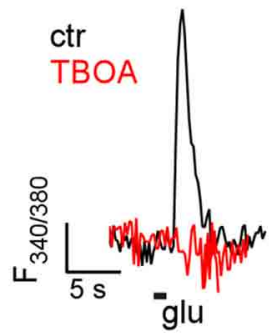

C
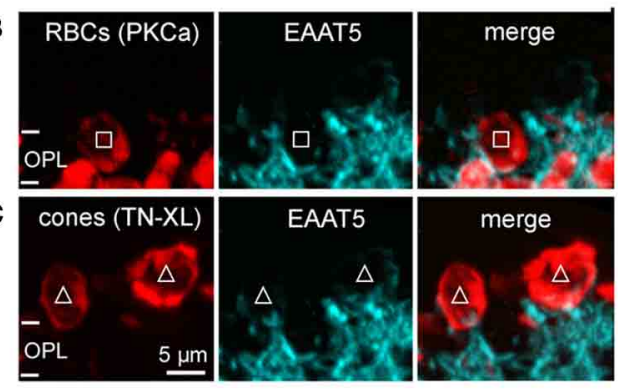

$\mathbf{F}$
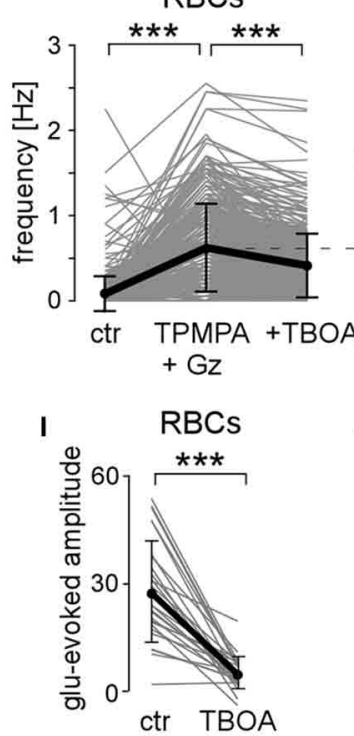

cell no.

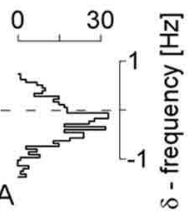

D

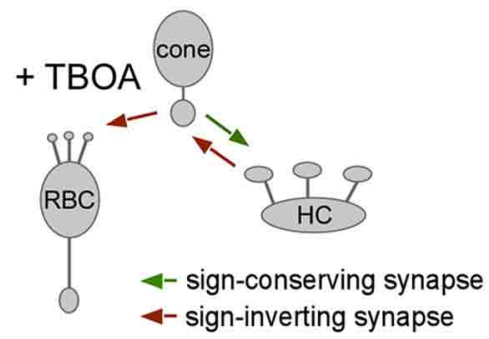

G

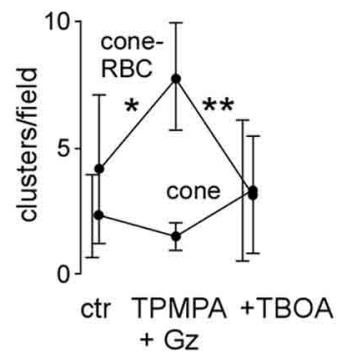

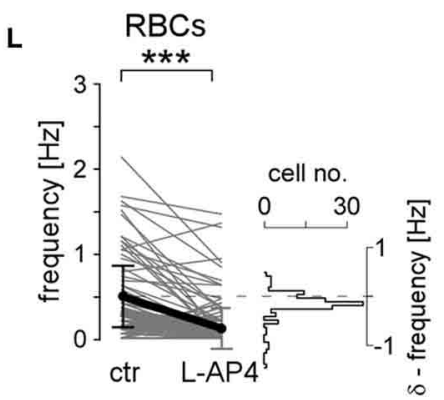

M

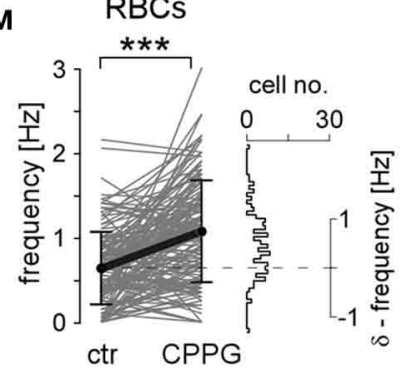

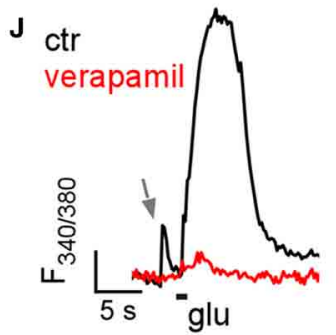

K

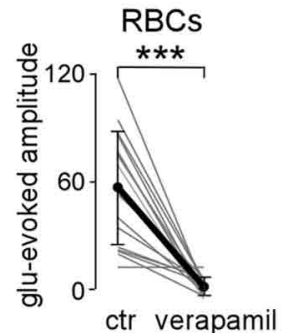

N

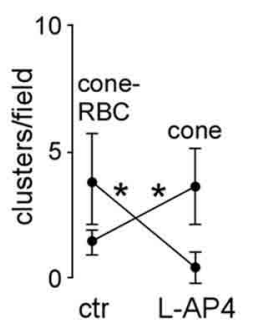

O

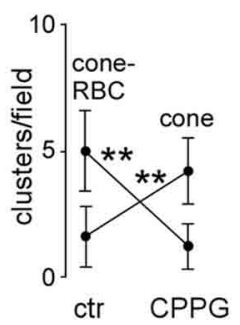

FIGURE 4 | Glutamate transporters mediate input from $r d 1$ cones to rod bipolar cells. (A-C) Vertical sections of $\mathrm{P} 35$ rd1 retina immunostained for EAAT5 ( $A-C$, cyan) and co-labeled for $\mathrm{RBCs}(B, \mathrm{PKC} \alpha$ in red, square) or cones ( $C, \mathrm{TN}-\mathrm{XL}$ in red, triangles). (D) Drawing shows synaptic interactions with glutamate transporter antagonist TBOA blocking sign-conserved cone input to RBCs. (E) Number of cone-RBC clusters before (ctr) and with TBOA. (F) Mean frequency $\left(F_{\text {mean }}\right)$ of $\mathrm{Ca}^{2+}$ transients in RBCs before (ctr), with GABA receptor blockers (TPMPA+Gz), and with TBOA applied in addition (+TBOA). (G) Effect of the drugs (from $F$ ) on the number of clusters. (H) Example recording showing glutamate puff-evoked $\mathrm{Ca}^{2+}$ signal in a $\mathrm{RBC}$ before (ctr, black) and with TBOA (red). (I) Effect of TBOA on the glutamate puff-evoked $\mathrm{Ca}^{2+}$ signal in RBCs $(n=26)$. (J) Example recording showing glutamate puff-evoked $\mathrm{Ca}^{2+}$ signal in a RBC before (ctr, black) and with verapamil (red); gray arrow indicates spontaneous $\mathrm{Ca}^{2+}$ transient. (K) Effect of verapamil on the glutamate puff-evoked $\mathrm{Ca}^{2+}$ signal in $\mathrm{RBCs}(n=17)$. (L,M) $F_{\text {mean }}$ in RBCs before, with the mGluR6 agonist L-AP4 $(L)$, and with the mGluR6 antagonist CPPG $(M)$. (N,O) Effect of L-AP4 and CPPG on cluster number. All error bars indicate s.e.m. glutamatergic transmission from cones to HCs but also feedback (and feedforward) input from HCs is altered. For example, in the wild-type mouse retina, ionotropic GABA receptors are expressed on HCs (Feigenspan and Weiler, 2004) acting as auto-receptors (Liu et al., 2013) but are not expressed on cones (Kemmler et al.,
2014), whereas $r d 1$ cones do express $\mathrm{GABA}_{\mathrm{A} / \mathrm{C}}$ receptors (Pattnaik et al., 2000). Notably, also GABAergic interplexiform cells form synapses in the outer retina (Dedek et al., 2009) and therefore may participate in controlling the activity of neurons in the outer $r d 1$ retina. 
A

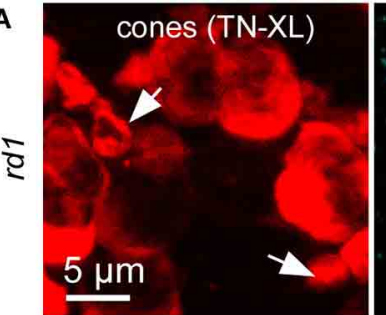

C

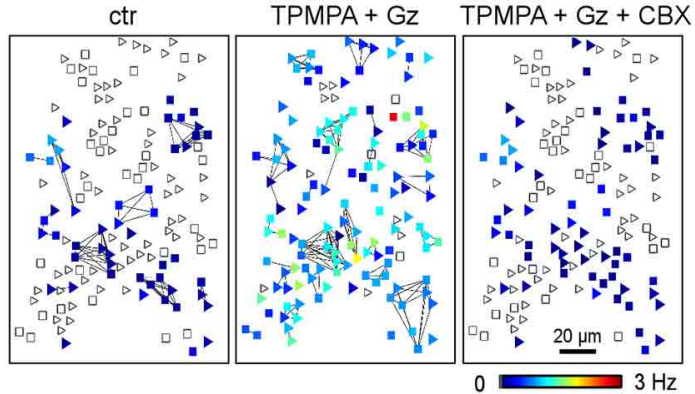

$\mathbf{F}$

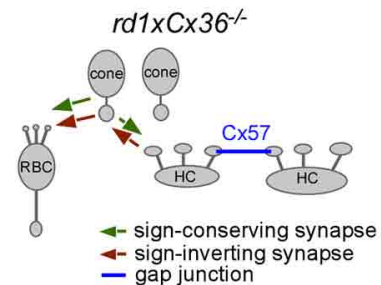

G

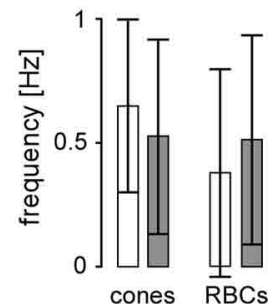

FIGURE 5 | Uncoupling of gap junctions between cones reduces correlated activity but not spontaneous activity. (A) Left: immunolabeling of a P30 rd1 wholemount retina showing cone somata (TN-XL, red) and smaller neurite protrusions. Middle: $\mathrm{C} \times 36$ immunolabeling (cyan) in same region. Right: overlay showing that cone neurite protrusions express $\mathrm{C} \times 36$ (arrows). (B) Drawing shows synaptic interactions with CBX blocking electrical coupling among cones and among $\mathrm{HCs}$ as well as possible ephaptic $\mathrm{HC}$ feedback. (C) Representative activity map before (ctr), with GABA receptor blockers (TPMPA+Gz), and with additional gap junction blocker CBX

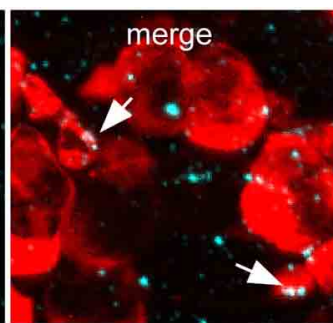

B

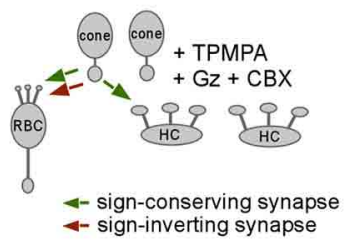

E
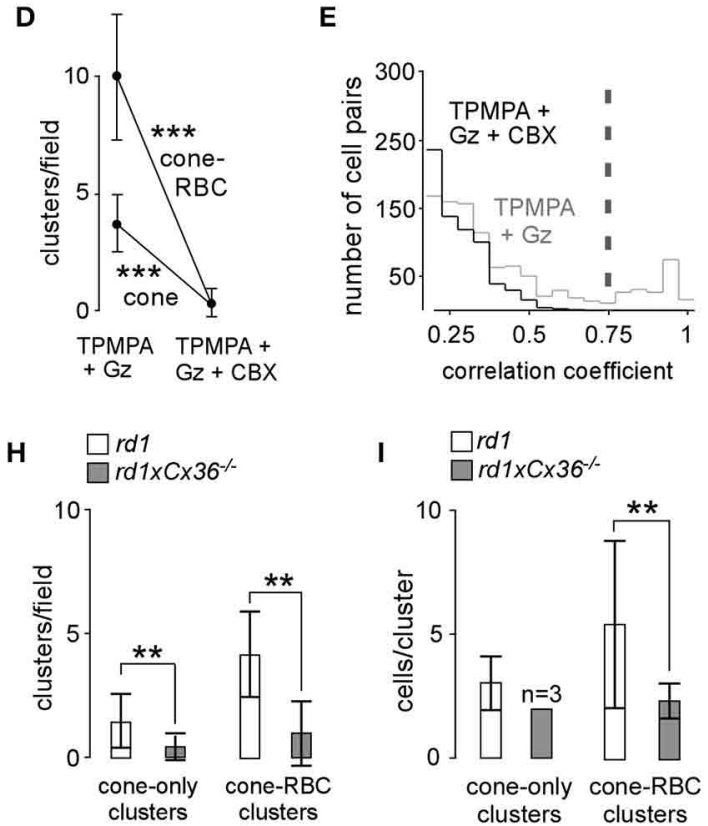

(cones, triangles; RBCs, squares). (D) Effect of the drugs on cluster number. (E) Distribution of correlation coefficients for control (gray line, TPMPA+Gz) and drug condition (black line, TPMPA $+\mathrm{Gz}+\mathrm{CBX}$ ). Gray dashed line indicates correlation coefficient $\geq 0.75$ used for our analysis. (F) Drawing illustrating the situation in the $r d 1 \times C \times 36^{-/-}$retina with cone-cone coupling selectively abolished. (G) Genetic deletion of Cx36 did not affect $F_{\text {mean }}$ (H) Comparison of cluster number in $r d 1$ and $\mathrm{C} \times 36$ knockout mice $\left(r d 1 \times \mathrm{C} \times 36^{-/-}\right)$. (I) Bar graphs showing that the cone-RBC cluster size was reduced in $r d 1 x$ $\mathrm{C} \times 36^{-/-}$. All error bars indicate s.e.m.

As shown above, GABAergic HC feedback (and potentially GABAergic inhibition provided by interplexiform cells) play a role in $r d 1$ outer retina in dampening cone and $\mathrm{RBC}$ spontaneous activity. GABA receptor blockers were particularly effective in disinhibiting cones, and likely as a consequence of increased cone input, also RBCs: in both cell types $F_{\text {mean }}$ (Figures 6A,B, Table 2, cf. Figure 5C) and the number of all cluster types increased significantly (Figures $\mathbf{6 C , H}$, Table 3). While the mean number of cells per cluster remained constant (Table 3), the cone/RBC ratio in cone-RBC clusters increased from 1 to 1.4 (Figure 6D), suggesting that $\mathrm{HCs}$ primarily modulate cone activity in $r d 1$. The disinhibitory effect of GABA receptor blockers may be mediated either directly by acting on the GABA receptors expressed by cone axon terminals, or additionally, indirectly by inhibiting HCs and reducing ephaptic HC feedback (Liu et al., 2013). Either way, GABAergic transmission results in modulation of cone activity. Additionally, the increase of cone-RBC cluster number in the presence of GABA receptor antagonists argues against a prominent GABAergic input from the inner retina on cluster activity, but of course, cannot exclude a general modulatory effect on RBC activity.

To "silence" HCs without having to block the different possible feedback pathways to cones, we suppressed their glutamatergic input using AMPA/kainate-type GluR antagonist NBQX. Application of NBQX had similar effects as Gabazine/TPMPA: (i) Some cones and RBCs that were not spontaneously active under control condition started to generate $\mathrm{Ca}^{2+}$ transients and (ii) activity increased in already active cones and RBCs (Figure 6E; Table 2). (iii) New activity clusters formed (Figures 6F,I; Table 3), and (iv) the cluster composition changed, with the cone/RBC ratio in cone-RBC clusters increasing from 0.8 to 1.3 (Figure 6G) while the average number of cells per cone-RBC cluster remained unaltered (Table 3). Thus, depriving HCs from their glutamatergic input resulted in a higher number of active cones and RBCs as 


\section{A}
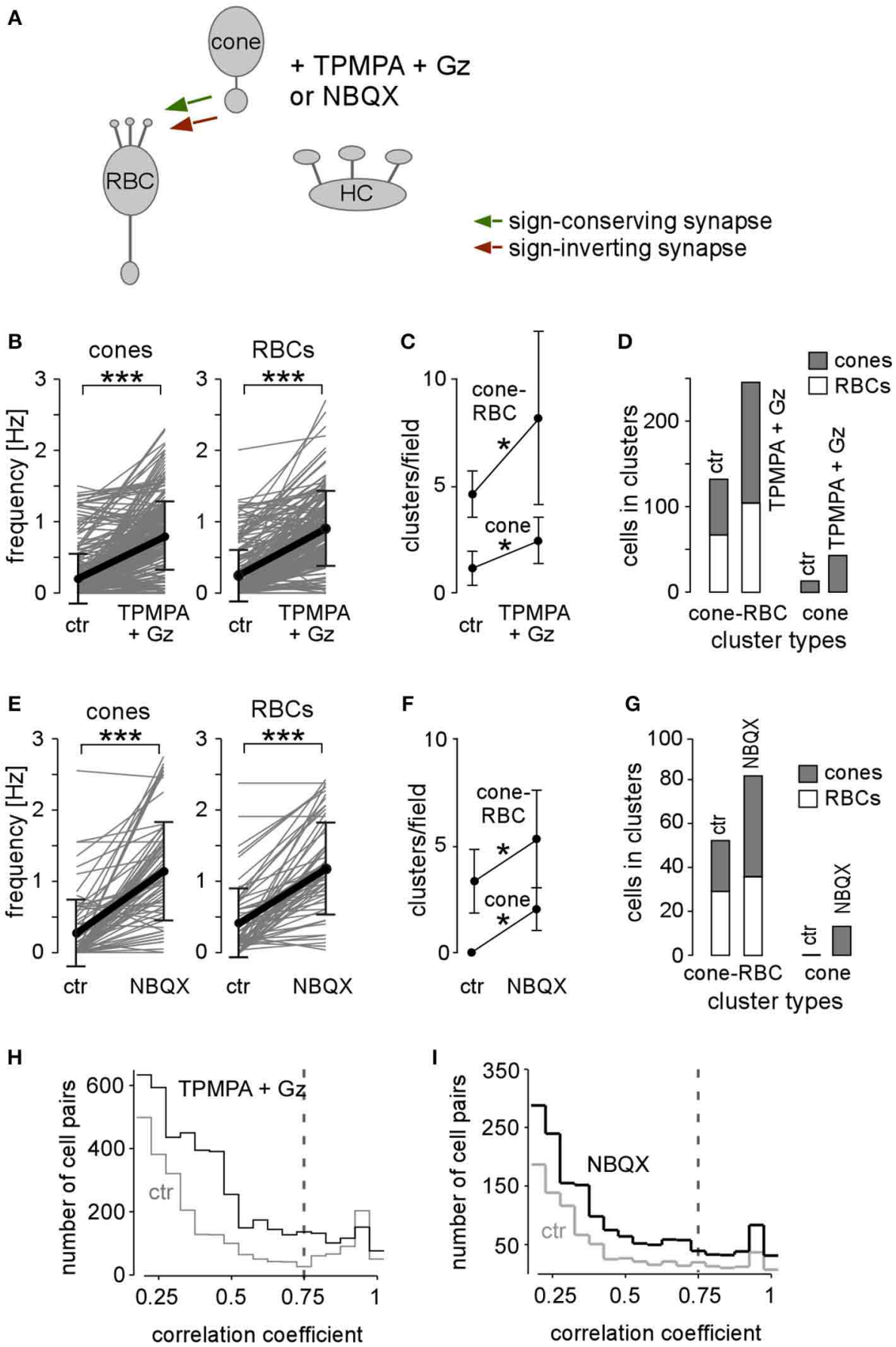

FIGURE 6 | Blocking HCs increases synchronous activity in cones and rod bipolar cells. (A) Drawing shows synaptic interactions of outer retinal neurons with GABA receptor antagonists (TPMPA+Gz) or AMPA/kainate-type GluR antagonist (NBQX). (B-D) Effect of TPMPA+Gz on $F_{\text {mean }}(B)$, cluster number $(C)$ and cluster composition $(D)$. (E-G)

Effect of NBQX on $F_{\text {mean }}(E)$, cluster number $(F)$ and cluster composition $(G)$. $(\mathbf{H}, \mathbf{I})$ Distribution of correlation coefficients for control (gray lines, ctr) and drug conditions [black lines: TPMPA $+\mathrm{Gz}(H)$, NBQX (//)]. Gray dashed line indicates correlation coefficient $\geq 0.75$ used for our analysis. All error bars indicate s.e.m.

well as more clusters. This indicates that spontaneous activity at least in $r d 1$ cones is directly attenuated by HCs, in line with our GABA receptor blocker results.

It is noteworthy that NBQX does not only affect HCs, but also inner retinal activity and, thus, potentially also feedback to the
OPL; i.e., via dopamine (Witkovsky, 2004). Nevertheless, we consider it unlikely that such feedback is responsible for the observed increase in cone and RBC activity, because dopamine effects are typically much slower (Witkovsky, 2004). Furthermore, the results of our glutamate puffing experiments (see Figures $4 \mathbf{H}-\mathbf{K}$ ) 
argue against the presence of ionotropic GluRs on $r d 1$ RBCsin contrast to what was reported for $r d 1 \mathrm{ON}$ cone bipolar cells (Chua et al., 2009)—and, thus, against a direct NBQX effect on RBCs.

\section{HORIZONTAL CELLS ARE FUNCTIONALLY COUPLED IN THE rd1 MOUSE RETINA}

In addition to the cone network, also HCs form an electrical network. Fura-2 loaded HCs were easily identified because of their regularly spaced large somata, as confirmed by subsequent immunostaining with antibodies against calbindin (Figures 7A,B). In strong contrast to the fragmented cluster activity of cones and RBCs, all HCs in a recorded field participated in a single activity cluster (Figure 7C). In wild-type mice, HCs form a large electrically coupled "syncytium" using Cx57 (Hombach et al., 2004). To test if the observed activity in the $r d 1$ HC network was synchronized by electrical coupling, we applied CBX and found that this eliminated $\mathrm{HC} \mathrm{Ca}{ }^{2+}$ activity almost completely (Figures 7C-E, Tables 2, 3). It is unlikely that the cone input to $\mathrm{HCs}$ was abolished by $\mathrm{CBX}$, because selective deletion of coupling between cones ( $r d 1 \times C \times 36^{-/-}$mouse) reduced the number and size of cone-only and cone-RBC clusters but did not significantly affect $F_{\text {mean }}$ in cones and RBCs (see above and Figures $\mathbf{5 F}-\mathbf{H}$ ). We therefore think that loss of $\mathrm{HC}$ activity was mainly due to CBX uncoupling the HC network, supporting the notion that HCs in $r d 1$ mice form a functional network that may spread oscillatory activity laterally in the outer retina. However, because such concerted HC activity was infrequently observed
A

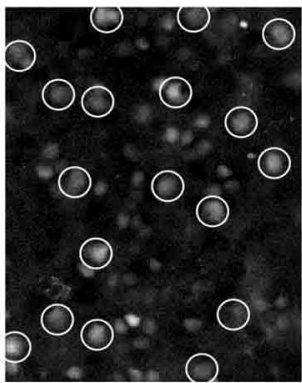

C

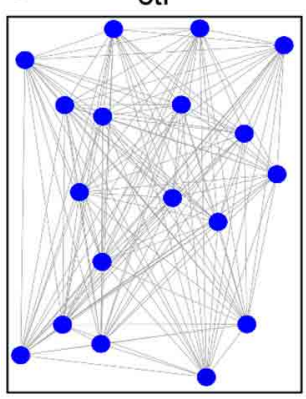

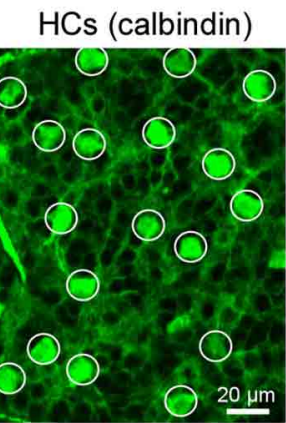

B

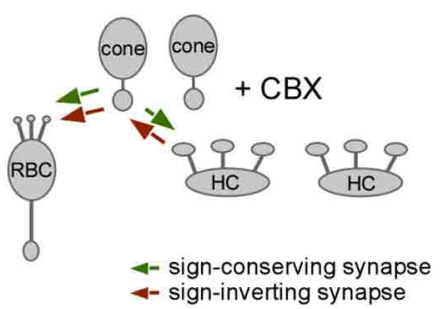

D

E
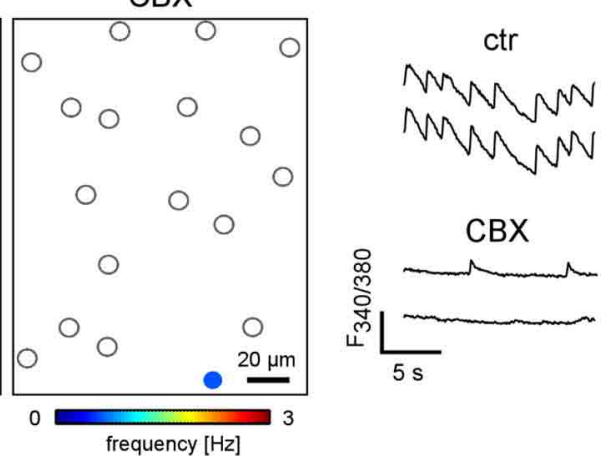

FIGURE 7 | Horizontal cells form a large electrically coupled network in the $\boldsymbol{r d} 1$ retina. (A) Left: Fura-2-labeled outer retinal neurons in P35 rd1 retina (open circles mark $\mathrm{HC}$ cell bodies). Right: consecutive immunolabeling of the same region for calbindin confirmed that the cells are HCs. (B) Drawing shows that the gap junction blocker carbenoxolone (CBX) blocks coupling between HCs (and cones). (C) Activity map before (ctr) and during the application of CBX. (D) Example $\mathrm{Ca}^{2+}$ traces of two $\mathrm{HCs}$ before and with CBX. (E) $\mathrm{CBX}$ reduced $F_{\text {mean }}$ in $\mathrm{HCs}$. All error bars indicate s.e.m. (F) Exemplary $\mathrm{Ca}^{2+}$ traces of two cones and one $\mathrm{HC}$ (asterisks indicate synchronous $\mathrm{Ca}^{2+}$ transients of the $\mathrm{HC}$ and two neighboring cones). (G) Histogram showing the time-binned distribution of cone $\mathrm{Ca}^{2+}$ transients ( $n=121$ ) relative to $\mathrm{HC}$ events ( $n=43$; aligned to $0 \mathrm{~ms} ; n=3$ retinas). 
( 3 out of 51 recorded fields), we did not investigate this aspect of $r d 1$ remodeling in detail.

\section{HORIZONTAL CELLS AND CONES SHOW SYNCHRONIZED ACTIVITY IN THE OUTER rd1 RETINA}

To analyze whether HC activity is driven by cone activity or, alternatively, $\mathrm{HCs}$ drive cones, we measured $\mathrm{Ca}^{2+}$ transients and determined $F_{\text {mean }}$ of consecutively identified HCs and cones (Figure 7G, Table 2). Typically, $\mathrm{Ca}^{2+}$ transients in HCs $(0.26 \pm$ $0.15 \mathrm{~Hz})$ coincided with cone $\mathrm{Ca}^{2+}$ transients $(0.53 \pm 0.42 \mathrm{~Hz})$, whereas not every cone transient was accompanied by a HC transient (Figure 7F). Quantification of events in the two cell types (time-binned histogram, Figure 7G) revealed that cone $\mathrm{Ca}^{2+}$ transients tended to precede $\mathrm{HC}$ events, indicating-within the limited resolution of our imaging system - that cones drive HC activity and not vice versa.

\section{DISCUSSION}

As a consequence of rod photoreceptor degeneration, the $r d 1$ mouse retina undergoes an extensive anatomical remodeling (reviewed in Jones and Marc, 2005), leading to spontaneous, light-independent activity in inner retinal neurons, such as ganglion cells (Stasheff, 2008). In the present study, we describe spontaneous activity in outer retinal neurons of the $r d 1$ mouse, and show that cones and RBCs form clusters of synchronized spontaneous activity. This correlated activity is mediated by synaptic contacts and mechanisms that result from remodeling and are atypical when compared to wild-type retina (for summary, see Figure 8): (i) Cones make functional synapses onto RBCs and (ii) signal transmission from cones to RBCs is predominantly mediated by glutamate transporters (likely EAAT5) rather than by mGluR6. (iii) This activity is attenuated by HC feedback, primarily via $\mathrm{GABA}_{\mathrm{A} / \mathrm{C}}$ receptors on cones rather than via a complex mechanism that involves GABA auto-receptors on HCs (Liu et al., 2013).

\section{MECHANISMS UNDERLYING SYNCHRONOUS OSCILLATORY ACTIVITY IN THE OUTER $\boldsymbol{r d 1}$ RETINA}

Due to secondary degeneration (Carter-Dawson et al., 1978), the cone mosaic in $r d 1$ retina is severely disturbed, with remnant cones forming small "island-like" aggregations. Despite the grave re-organization of their synapses (e.g., Strettoi and Pignatelli, 2000), $r d 1$ cones express the gap junction-forming Cx36, as reported for wild-type cones (Feigenspan et al., 2004). Instead of a global gap junctionally-coupled network, $r d 1$ cones therefore form multiple local networks. Indeed, with cone coupling genetically ablated, activity was asynchronous, suggesting that cone coupling within clusters plays an important role in synchronizing and possibly enhancing oscillatory activity in the $r d 1$ outer retina. We therefore propose that spontaneous activity in the outer $r d 1$ retina originates in electrically coupled remnant cones-complementary to the inner retina where spontaneous activity originates in the AII/ON-cone bipolar cell network (Borowska et al., 2011; Trenholm et al., 2012).

What is the mechanism underlying intrinsic spontaneous activity in $r d 1$ cones? Our data show that cone activity was

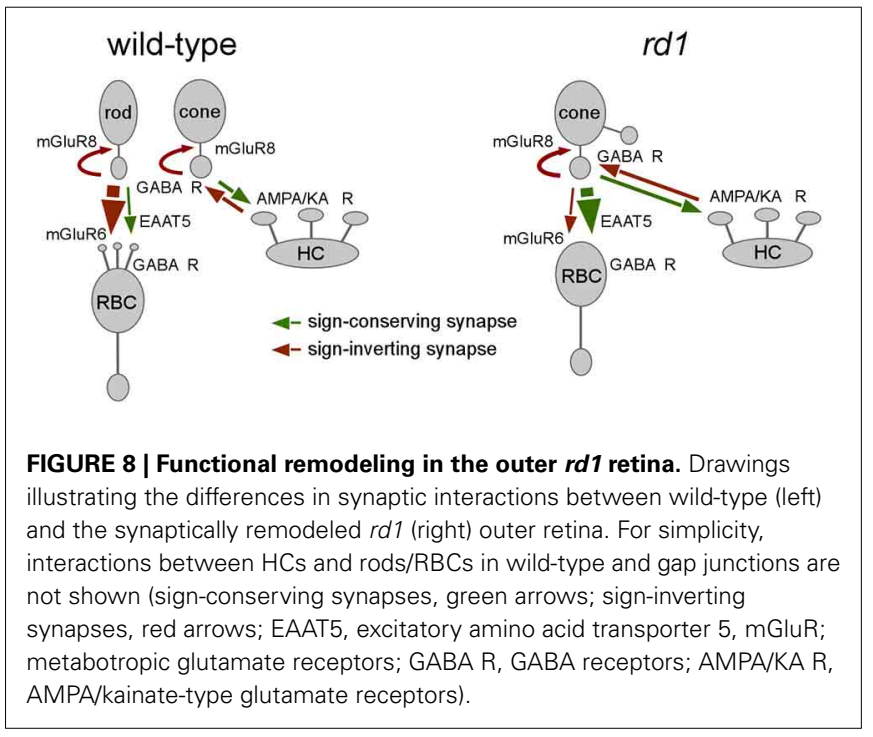

abolished by blocking VGCCs, indicating that fluctuations in cone membrane potential are involved. Indeed, wild-type cones were shown to possess regenerative membrane properties that can lead to spiking (reviewed in Baden et al., 2013), as demonstrated for primate cones (Schnapf et al., 1990). In mouse cones, spike-like $\mathrm{Ca}^{2+}$ events were also observed in recordings of vertical retina slices (Wei et al., 2012). Interestingly, while many cones showed signs of active currents (i.e., rebound $\mathrm{Ca}^{2+}$ transients at light-offset; cf. Figure 4 in Wei et al., 2012), only few mouse cones actually displayed spiking activity. It is tempting to compare the situation at the surface of a retinal wild-type slice with the $r d 1$ outer retina, since in both cases stringent control of cone output by $\mathrm{HC}$ feedback might be disturbed: in the slice by mechanical damage, and in $r d 1$ as a consequence of remodeling. In the intact retina, ON bipolar cells and HCs contact cone pedicles with invaginating contacts (Boycott and Wässle, 1999; Haverkamp et al., 2000) forming an enclosed, complex multi-synaptic structure. This well-defined structure serves to precisely control glutamate release from cones, and provides the microenvironment necessary for hemichannel-mediated ephaptic HC-cone feedback (reviewed in Kamermans and Fahrenfort, 2004), likely modulated by GABA auto-receptors on HCs (Liu et al., 2013). In $r d 1$, the cone synapse is likely less "encapsulated" due to synaptic re-wiring of cone pedicles with RBCs (Peng et al., 2000), and therefore the feedback is likely less effective, leading to cone depolarization and the observed spontaneous activity, which then propagates within the local cone network. As indicated by Pattnaik et al. (2000), $r d 1$ cones possess GABA receptors - in contrast to the situation in wild-type (Kemmler et al., 2014)—and therefore a GABAergic HC-cone feedback is likely functional but by itself may not be sufficient to prevent spontaneous cone activity. In addition, $r d 1$ cones lose their outer segments and thus their source of light-evoked hyperpolarization. Consequently, the $r d 1$ cone membrane potential may be more depolarized than in intact cones, making it more likely that potential fluctuations reach the VGCCs' activation threshold. 


\section{SYNCHRONOUS ACTIVITY IN $\boldsymbol{r d 1}$ CONES AND ROD BIPOLAR CELLS}

One important finding of this study is that $r d 1$ RBCs receive glutamatergic cone input primarily via sign-conserving synapses that involve glutamate transporters (likely EAAT5). Sign-inverting mGluR6, which mediate sign-inverting input from rods to RBCs in the wild-type retina, appears to play a minor role, an observation that is in agreement with a previous study showing that $r d 1$ RBCs are much less sensitive for mGluR6 agonists (Chua et al., 2009). The decrease in mGluR6 on $r d 1$ RBCs may be related to the fact that the mGluR6 complex comprises a plethora of different membrane and cytoplasmic proteins, including the receptor itself, a G protein, nyctalopin and TRPM1 channels (Cao et al., 2011). It is therefore conceivable that mGluR6-dependent transmission is more vulnerable to degeneration-induced imbalances in protein expression level (Hauck et al., 2006) - the downregulation of proteins such mGluR6 and TRPM1 (Strettoi and Pignatelli, 2000; Krizaj et al., 2010) may be sufficient to inactivate the mGluR6 signaling cascade. In contrast, the here described EAAT-mediated transmission pathway in $r d 1$ retina relies on the expression of a single trans-membrane protein, which is already present on wild-type RBCs (EAAT5, see Wersinger et al., 2006), making it a suitable candidate to dominate transmission in the newly formed, ectopic cone-RBC synapses. It is possible that the remodeled, possibly "leaky" synapse between cones and RBCs promotes an EAAT-mediated pathway, as glutamate released from the cone may diffuse further ("spill-over") than in the wild-type situation. However, in view of the dendritic/somatic EAAT expression we found in $r d 1$ RBCs, action of glutamate at the distal bipolar cell end is most probable. Also, if glutamate released from cones actually were diffusing to RBC axon terminals, a hyperpolarizing response would be expected, as $\mathrm{Cl}^{-}$concentration is low in the RBC terminals (Billups and Attwell, 2002; Varela et al., 2005), resulting in an EAAT-mediated $\mathrm{Cl}^{-}$influx.

\section{FUNCTIONAL RELEVANCE FOR INNER RETINAL NETWORKS}

How does the spontaneous activity in cones and RBCs relate to the oscillations described earlier in the inner $r d 1$ retina? In wild-type retina, RBCs synapse onto AIIs (Bloomfield and Dacheux, 2001) and, thus, RBCs could relay the spontaneous cone activity to inner retinal neurons. While RBC axon terminals are structurally intact and AIIs are functional in $r d 1$ (Borowska et al., 2011), it is still unclear whether the RBC-AII synapse is functionally intact (Barhoum et al., 2008). Because blocking glutamatergic input from bipolar cells (including RBCs) failed to abolish oscillatory activity in the degenerating inner retina, it was proposed that the electrically-coupled AII/ONcone bipolar cell network by itself is sufficient for initiating the oscillations (Borowska et al., 2011; Yee et al., 2012; Margolis et al., 2014). Additionally, the frequency of oscillatory events in $r d 1$ inner retinal neurons is higher $(>10 \mathrm{~Hz})$ than that of the $\mathrm{Ca}^{2+}$ signals in outer retina neurons $(<3 \mathrm{~Hz})$ observed in this study. This argues against the outer retina as the sole source of inner retina activity, but it does not exclude a contribution of outer retinal activity, i.e., via RBCs and possibly other bipolar cell types. Taken together, oscillatory activity in the $r d 1$ retina is likely generated independently by electrically coupled networks consisting of cones in the outer and AIIs/ON-cone bipolar cells in the inner retina. An important difference, however, may be that the activity in the outer $r d 1$ retina results from synaptic remodeling, whereas for the inner retina a correlation between aberrant activity and structural changes has not (yet) been described.

\section{IMPLICATION OF SPONTANEOUS ACTIVITY IN rd1 RETINA ON THERAPEUTIC APPROACHES FOR VISION RESCUE}

Spontaneous activity in the retina of blind human patients has not yet been directly recorded. Nevertheless, patients with retinal degenerative disorders, such as Retinitis Pigmentosa or agerelated macular degeneration, often report a discomforting "misperception" of bright, light-independent flashes, a phenomenon described as photopsia (Bittner et al., 2009). It is conceivable that the spontaneous activity described in the $r d 1$ mouse also exists in retinal degeneration patients, potentially manifesting as photopsia. Moreover, photopsia poses a severe problem for the development of therapeutic strategies, such as electrical retinal implants (Klauke et al., 2011; Zrenner, 2013) and optogenetic approaches (Lagali et al., 2008). Recently, the implantation of electrical prostheses demonstrated partial restoration of limited vision at advanced stages of photoreceptor degeneration in humans: treated patients were able to distinguish basic geometric forms, read large letters and even discriminate facial expressions. However, some patients reported "blurring" of visual stimuli that exceeded what was to be expected from the spatial and temporal resolution of the implant chip (Zrenner et al., 2011). A possible explanation may be that signal transmission efficiency from the implant to second-order retinal neurons is reduced and degraded by spontaneous activity in the retinal network. For the same reason, optogenetic approaches that aim at rendering remnant photoreceptors or second-order neurons lightsensitive (Lagali et al., 2008), potentially suffer from spontaneous activity in the degenerating retinal network. As reported here, disrupting the electrically coupled retinal networks genetically or pharmacologically largely abolished synchronous oscillations of $r d 1$ outer retinal neurons. Similar effects of gap junction blockers were reported for the spontaneous activity in the inner retina (Borowska et al., 2011; Menzler and Zeck, 2011; Toychiev et al., 2013). Therefore, uncoupling electrical networks in the retina, e.g., by (more selective and, importantly, non-toxic) gap junction blockers, may possess therapeutic potential for treating photopsia.

\section{ACKNOWLEDGMENTS}

We thank G. Eske and S. Bolz for excellent technical assistance, T. Baden, B. Antkowiak, R. Kemmler and F. Paquet-Durand for critical reading of the manuscript, and $\mathrm{K}$. Kranz and K. Dedek for providing transgenic mice. This work was supported by the Deutsche Forschungsgemeinschaft (EXC 307, CIN to Thomas Euler, Timm Schubert) and the German Federal Ministry of Education and Research (ANI-FKZ 16SV3891 to Wadood Haq, Eberhart Zrenner, HOPE2FKZ 01GM1108A to Blanca Arango-Gonzalez, BCCN-FKZ 01GQ1002 to Wadood Haq, Eberhart Zrenner, Thomas Euler). 


\section{REFERENCES}

Arriza, J. L., Eliasof, S., Kavanaugh, M. P., and Amara, S. G. (1997). Excitatory amino acid transporter 5, a retinal glutamate transporter coupled to a chloride conductance. Proc. Natl. Acad. Sci. U.S.A 94, 4155-4160. doi: 10.1073/pnas.94. 8.4155

Baden, T., Euler, T., Weckström, M., and Lagnado, L. (2013). Spikes and ribbon synapses in early vision. Trends Neurosci. 36, 480-488. doi: 10.1016/j.tins.2013. 04.006

Barhoum, R., Martinez-Navarrete, G., Corrochano, S., Germain, F., FernandezSanchez, L., De La Rosa, E. J., et al. (2008). Functional and structural modifications during retinal degeneration in the rd10 mouse. Neuroscience 155, 698-713. doi: 10.1016/j.neuroscience.2008.06.042

Berrebi, A. S., Oberdick, J., Sangameswaran, L., Christakos, S., Morgan, J. I., and Mugnaini, E. (1991). Cerebellar Purkinje cell markers are expressed in retinal bipolar neurons. J. Comp. Neurol. 308, 630-649. doi: 10.1002/cne. 903080409

Billups, D., and Attwell, D. (2002). Control of intracellular chloride concentration and GABA response polarity in rat retinal ON bipolar cells. J. Physiol. 545, 183-198. doi: 10.1113/jphysiol.2002.024877

Bittner, A. K., Diener-West, M., and Dagnelie, G. (2009). A survey of photopsias in self-reported retinitis pigmentosa: location of photopsias is related to disease severity. Retina 29, 1513-1521. doi: 10.1097/IAE.0b013e3181af0d57

Bloomfield, S. A., and Dacheux, R. F. (2001). Rod vision: pathways and processing in the mammalian retina. Prog. Retin. Eye Res. 20, 351-384. doi: 10.1016/S13509462(00)00031-8

Borowska, J., Trenholm, S., and Awatramani, G. B. (2011). An intrinsic neural oscillator in the degenerating mouse retina. J. Neurosci. 31, 5000-5012. doi: 10.1523/JNEUROSCI.5800-10.2011

Bowes, C., Li, T., Danciger, M., Baxter, L. C., Applebury, M. L., and Farber, D. B. (1990). Retinal degeneration in the rd mouse is caused by a defect in the beta subunit of rod cGMP-phosphodiesterase. Nature 347, 677-680. doi: $10.1038 / 347677 \mathrm{a} 0$

Boycott, B., and Wässle, H. (1999). Parallel processing in the mammalian retina: the Proctor Lecture. Invest. Ophthalmol. Vis. Sci. 40, 1313-1327.

Busskamp, V., Duebel, J., Balya, D., Fradot, M., Viney, T. J., Siegert, S., et al. (2010). Genetic reactivation of cone photoreceptors restores visual responses in retinitis pigmentosa. Science 329, 413-417. doi: 10.1126/science.1190897

Cao, Y., Posokhova, E., and Martemyanov, K. A. (2011). TRPM1 forms complexes with nyctalopin in vivo and accumulates in postsynaptic compartment of ONbipolar neurons in mGluR6-dependent manner. J. Neurosci. 31, 11521-11526. doi: 10.1523/JNEUROSCI.1682-11.2011

Carter-Dawson, L. D., Lavail, M. M., and Sidman, R. L. (1978). Differential effect of the rd mutation on rods and cones in the mouse retina. Invest. Ophthalmol. Vis. Sci. 17, 489-498.

Chua, J., Fletcher, E. L., and Kalloniatis, M. (2009). Functional remodeling of glutamate receptors by inner retinal neurons occurs from an early stage of retinal degeneration. J. Comp. Neurol. 514, 473-491. doi: 10.1002/cne.22029

Cuenca, N., Pinilla, I., Sauve, Y., Lu, B., Wang, S., and Lund, R. D. (2004). Regressive and reactive changes in the connectivity patterns of rod and cone pathways of $\mathrm{P} 23 \mathrm{H}$ transgenic rat retina. Neuroscience 127, 301-317. doi: 10.1016/j.neuroscience.2004.04.042

Dedek, K., Breuninger, T., de Sevilla Müller, L. P., Maxeiner, S., Schultz, K., Janssen-Bienhold, U., et al. (2009). A novel type of interplexiform amacrine cell in the mouse retina. Eur. J. Neurosci. 30, 217-228. doi: 10.1111/j.14609568.2009.06808.x

Fairman, W. A., Vandenberg, R. J., Arriza, J. L., Kavanaugh, M. P., and Amara, S. G. (1995). An excitatory amino-acid transporter with properties of a ligand-gated chloride channel. Nature 375, 599-603. doi: 10.1038/375599a0

Feigenspan, A., Janssen-Bienhold, U., Hormuzdi, S., Monyer, H., Degen, J., Sohl, G., et al. (2004). Expression of connexin36 in cone pedicles and OFF-cone bipolar cells of the mouse retina. J. Neurosci. 24, 3325-3334. doi: 10.1523/JNEUROSCI. 5598-03.2004

Feigenspan, A., and Weiler, R. (2004). Electrophysiological properties of mouse horizontal cell GABAA receptors. J. Neurophys. 92, 2789-2801. doi: 10.1152/ jn.00284.2004

Garcia-Fernandez, J. M., Jimenez, A. J., and Foster, R. G. (1995). The persistence of cone photoreceptors within the dorsal retina of aged retinally degenerate mice (rd/rd): implications for circadian organization. Neurosci. Lett. 187, 33-36. doi: 10.1016/0304-3940(95)11330-Y
Grant, G. B., and Dowling, J. E. (1995). A glutamate-activated chloride current in cone-driven ON bipolar cells of the white perch retina. J. Neurosci. 15, 3852-3862.

Grynkiewicz, G., Poenie, M., and Tsien, R. Y. (1985). A new generation of $\mathrm{Ca}^{2+}$ indicators with greatly improved fluorescence properties. J. Biol. Chem. 260, 3440-3450.

Güldenagel, M., Ammermüller, J., Feigenspan, A., Teubner, B., Degen, J., Sohl, G., et al. (2001). Visual transmission deficits in mice with targeted disruption of the gap junction gene connexin36. J. Neurosci. 21, 6036-6044.

Hauck, S. M., Ekström, P. A., Ahuja-Jensen, P., Suppmann, S., Paquet-Durand, F., Van Veen, T., et al. (2006). Differential modification of phosducin protein in degenerating $\mathrm{rd} 1 \mathrm{retina}$ is associated with constitutively active $\mathrm{Ca} 2+/$ calmodulin kinase II in rod outer segments. Mol. Cell. Proteomics 5, 324-336. doi: 10.1074/mcp.M500217-MCP200

Haverkamp, S., Grünert, U., and Wässle, H. (2000). The cone pedicle, a complex synapse in the retina. Neuron 27, 85-95. doi: 10.1016/S0896-6273(00)00011-8

Hombach, S., Janssen-Bienhold, U., Sohl, G., Schubert, T., Bussow, H., Ott, T., et al. (2004). Functional expression of connexin57 in horizontal cells of the mouse retina. Eur. J. Neurosci. 19, 2633-2640. doi: 10.1111/j.0953-816X.2004. 03360.x

Jimenez, A. J., Garcia-Fernandez, J. M., Gonzalez, B., and Foster, R. G. (1996). The spatio-temporal pattern of photoreceptor degeneration in the aged $\mathrm{rd} / \mathrm{rd}$ mouse retina. Cell Tissue Res. 284, 193-202. doi: 10.1007/s004410050579

Jones, B. W., and Marc, R. E. (2005). Retinal remodeling during retinal degeneration. Exp. Eye Res. 81, 123-137. doi: 10.1016/j.exer.2005.03.006

Kamermans, M., and Fahrenfort, I. (2004). Ephaptic interactions within a chemical synapse: hemichannel-mediated ephaptic inhibition in the retina. Curr. Opin. Neurobiol. 14, 531-541. doi: 10.1016/j.conb.2004.08.016

Kemmler, R., Schultz, K., Dedek, K., Euler, T., and Schubert, T. (2014). Differential regulation of cone calcium signals by different horizontal cell feedback mechanisms in the mouse retina. J. Neurosci. 34, 11826-11843. doi: 10.1523/JNEUROSCI.0272-14.2014

Klauke, S., Goertz, M., Rein, S., Hoehl, D., Thomas, U., Eckhorn, R., et al. (2011). Stimulation with a wireless intraocular epiretinal implant elicits visual percepts in blind humans. Invest. Ophthalmol. Vis. Sci. 52, 449-455. doi: 10.1167/iovs.094410

Koulen, P., Kuhn, R., Wässle, H., and Brandstätter, J. H. (1999). Modulation of the intracellular calcium concentration in photoreceptor terminals by a presynaptic metabotropic glutamate receptor. Proc. Natl. Acad. Sci. U.S.A. 96, 9909-9914. doi: 10.1073/pnas.96.17.9909

Krizaj, D., Huang, W., Furukawa, T., Punzo, C., and Xing, W. (2010). Plasticity of TRPM1 expression and localization in the wild type and degenerating mouse retina. Vision Res. 50, 2460-2465. doi: 10.1016/j.visres.2010.08.034

Lagali, P. S., Balya, D., Awatramani, G. B., Münch, T. A., Kim, D. S., Busskamp, V., et al. (2008). Light-activated channels targeted to ON bipolar cells restore visual function in retinal degeneration. Nat. Neurosci. 11, 667-675. doi: 10.1038/ nn. 2117

Lambrecht, H. G., and Koch, K. W. (1992). Recoverin, a novel calcium-binding protein from vertebrate photoreceptors. Biochim. Biophys. Acta 1160, 63-66. doi: 10.1016/0167-4838(92)90038-F

Lin, B., Masland, R. H., and Strettoi, E. (2009). Remodeling of cone photoreceptor cells after rod degeneration in rd mice. Exp. Eye Res. 88, 589-599. doi: 10.1016/ j.exer.2008.11.022

Liu, X., Hirano, A. A., Sun, X., Brecha, N. C., and Barnes, S. (2013). Calcium channels in rat horizontal cells regulate feedback inhibition of photoreceptors through an unconventional GABA- and pH-sensitive mechanism. J. Physiol. 591, 3309-3324. doi: 10.1113/jphysiol.2012.248179

Margolis, D. J., Gartland, A. J., Singer, J. H., and Detwiler, P. B. (2014). Network Oscillations Drive correlated spiking of on and off ganglion cells in the rd 1 mouse model of retinal degeneration. PLoS ONE 9:e86253. doi: 10.1371/journal.pone.0086253

Margolis, D. J., Newkirk, G., Euler, T., and Detwiler, P. B. (2008). Functional stability of retinal ganglion cells after degeneration-induced changes in synaptic input. J. Neurosci. 28, 6526-6536. doi: 10.1523/JNEUROSCI.1533-08.2008

Menzler, J., and Zeck, G. (2011). Network oscillations in rod-degenerated mouse retinas. J. Neurosci. 31, 2280-2291. doi: 10.1523/JNEUROSCI.423810.2011

Morgans, C. W., Zhang, J., Jeffrey, B. G., Nelson, S. M., Burke, N. S., Duvoisin, R. M., et al. (2009). TRPM1 is required for the depolarizing light response in 
retinal ON-bipolar cells. Proc. Natl. Acad. Sci. U.S.A. 106, 19174-19178. doi: 10.1073/pnas.0908711106

Nachman-Clewner, M., St. Jules, R., and Townes-Anderson, E. (1999). L-type calcium channels in the photoreceptor ribbon synapse: localization and role in plasticity. J. Comp. Neurol. 415, 1-16.

Nakajima, Y., Iwakabe, H., Akazawa, C., Nawa, H., Shigemoto, R., Mizuno, N., et al. (1993). Molecular characterization of a novel retinal metabotropic glutamate receptor mGluR6 with a high agonist selectivity for L-2-amino-4phosphonobutyrate. J. Biol. Chem. 268, 11868-11873.

Pang, J. J., Gao, F., Lem, J., Bramblett, D. E., Paul, D. L., and Wu, S. M. (2010). Direct rod input to cone BCs and direct cone input to rod BCs challenge the traditional view of mammalian BC circuitry. Proc. Natl. Acad. Sci. U.S.A. 107, 395-400. doi: 10.1073/pnas.0907178107

Pasteels, B., Rogers, J., Blachier, F., and Pochet, R. (1990). Calbindin and calretinin localization in retina from different species. Vis. Neurosci. 5, 1-16. doi: 10.1017/S0952523800000031

Pattnaik, B., Jellali, A., Sahel, J., Dreyfus, H., and Picaud, S. (2000). GABAC receptors are localized with microtubule-associated protein $1 \mathrm{~B}$ in mammalian cone photoreceptors. J. Neurosci. 20, 6789-6796.

Peng, Y. W., Hao, Y., Petters, R. M., and Wong, F. (2000). Ectopic synaptogenesis in the mammalian retina caused by rod photoreceptor-specific mutations. Nat. Neurosci. 3, 1121-1127. doi: 10.1038/80639

Picaud, S., Larsson, H. P., Wellis, D. P., Lecar, H., and Werblin, F. (1995). Cone photoreceptors respond to their own glutamate release in the tiger salamander. Proc. Natl. Acad. Sci. U.S.A. 92, 9417-9421. doi: 10.1073/pnas.92.20.9417

Protti, D. A., and Llano, I. (1998). Calcium currents and calcium signaling in rod bipolar cells of rat retinal slices. J. Neurosci. 18, 3715-3724.

Rossi, C., Strettoi, E., and Galli-Resta, L. (2003). The spatial order of horizontal cells is not affected by massive alterations in the organization of other retinal cells. J. Neurosci. 23, 9924-9928.

Schnapf, J. L., Nunn, B. J., Meister, M., and Baylor, D. A. (1990). Visual transduction in cones of the monkey Macaca fascicularis. J. Physiol. 427, 681-713.

Schubert, T., Weiler, R., and Feigenspan, A. (2006). Intracellular calcium is regulated by different pathways in horizontal cells of the mouse retina. J. Neurophysiol. 96, 1278-1292. doi: 10.1152/jn.00191.2006

Stasheff, S. F. (2008). Emergence of sustained spontaneous hyperactivity and temporary preservation of OFF responses in ganglion cells of the retinal degeneration (rd1) mouse. J. Neurophysiol. 99, 1408-1421. doi: 10.1152/jn.00144.2007

Strettoi, E., and Pignatelli, V. (2000). Modifications of retinal neurons in a mouse model of retinitis pigmentosa. Proc. Natl. Acad. Sci. U.S.A. 97, 11020-11025. doi: 10.1073/pnas.190291097

Ströh, S., Sonntag, S., Janssen-Bienhold, U., Schultz, K., Cimiotti, K., Weiler, R., et al. (2013). Cell-specific cre recombinase expression allows selective ablation of glutamate receptors from mouse horizontal cells. PLoS ONE 8:e83076. doi: 10.1371/journal.pone.0083076

Thoreson, W. B., and Mangel, S. C. (2012). Lateral interactions in the outer retina. Prog. Retin. Eye Res. 31, 407-441. doi: 10.1016/j.preteyeres.2012.04.003

Toychiev, A. H., Ivanova, E., Yee, C. W., and Sagdullaev, B. T. (2013). Block of gap junctions eliminates aberrant activity and restores light responses during retinal degeneration. J. Neurosci. 33, 13972-13977. doi: 10.1523/JNEUROSCI.239913.2013
Trenholm, S., Borowska, J., Zhang, J., Hoggarth, A., Johnson, K., Barnes, S., et al. (2012). Intrinsic oscillatory activity arising within the electrically coupled AII amacrine-ON cone bipolar cell network is driven by voltagegated Na+ channels. J. Physiol. 590, 2501-2517. doi: 10.1113/jphysiol.2011. 225060

Varela, C., Blanco, R., and De La Villa, P. (2005). Depolarizing effect of GABA in rod bipolar cells of the mouse retina. Vision Res. 45, 2659-2667. doi: 10.1016/j. visres.2005.03.020

Vessey, J. P., Lalonde, M. R., Mizan, H. A., Welch, N. C., Kelly, M. E., and Barnes, S. (2004). Carbenoxolone inhibition of voltage-gated Ca channels and synaptic transmission in the retina. J. Neurophysiol. 92, 1252-1256. doi: 10.1152/jn. 00148.2004

Wei, T., Schubert, T., Paquet-Durand, F., Tanimoto, N., Chang, L., Koeppen, K., et al. (2012). Light-driven calcium signals in mouse cone photoreceptors. J. Neurosci. 32, 6981-6994. doi: 10.1523/JNEUROSCI.6432-11. 2012

Wersinger, E., Schwab, Y., Sahel, J. A., Rendon, A., Pow, D. V., Picaud, S., et al. (2006). The glutamate transporter EAAT5 works as a presynaptic receptor in mouse rod bipolar cells. J. Physiol. 577, 221-234. doi: 10.1113/jphysiol.2006.118281

Witkovsky, P. (2004). Dopamine and retinal function. Doc. Ophthalmol. 108, 17-40. doi: 10.1023/B:DOOP.0000019487.88486.0a

Ye, J. H., and Goo, Y. S. (2007). The slow wave component of retinal activity in $\mathrm{rd} / \mathrm{rd}$ mice recorded with a multi-electrode array. Physiol. Meas. 28, 1079-1088. doi: 10.1088/0967-3334/28/9/009

Yee, C. W., Toychiev, A. H., and Sagdullaev, B. T. (2012). Network deficiency exacerbates impairment in a mouse model of retinal degeneration. Front. Syst. Neurosci. 6:8. doi: 10.3389/fnsys.2012.00008

Zrenner, E. (2013). Fighting blindness with microelectronics. Sci. Transl. Med. 5, 210ps216. doi: 10.1126/scitranslmed.3007399

Zrenner, E., Bartz-Schmidt, K. U., Benav, H., Besch, D., Bruckmann, A., Gabel, V. P., et al. (2011). Subretinal electronic chips allow blind patients to read letters and combine them to words. Proc. Biol. Sci. 278, 1489-1497. doi: 10.1098/rspb. 2010.1747

Conflict of Interest Statement: The authors declare that the research was conducted in the absence of any commercial or financial relationships that could be construed as a potential conflict of interest.

Received: 15 July 2014; accepted: 19 August 2014; published online: 05 September 2014. Citation: Haq W, Arango-Gonzalez B, Zrenner E, Euler T and Schubert T (2014) Synaptic remodeling generates synchronous oscillations in the degenerated outer mouse retina. Front. Neural Circuits 8:108. doi: 10.3389/fncir.2014.00108 This article was submitted to the journal Frontiers in Neural Circuits. Copyright (C) 2014 Haq, Arango-Gonzalez, Zrenner, Euler and Schubert. This is an open-access article distributed under the terms of the Creative Commons Attribution License (CC BY). The use, distribution or reproduction in other forums is permitted, provided the original author(s) or licensor are credited and that the original publication in this journal is cited, in accordance with accepted academic practice. No use, distribution or reproduction is permitted which does not comply with these terms. 